Recibido: septiembre de 2016

Aprobado: octubre de 2016

$\mathrm{DOI}$

http://dx.doi.org/10.15332/rev.m.v13i0.1995

Disputa por la ciudad entre el mercado inmobiliario y las favelas en São Paulo (Paraisópolis)

Fuente: Adaptación - Archivo de imágenes de los autores 2015 (notas de clases).

\section{AMÉRICA LATINA URBANA: EL HÁBITAT DEL SIGLO XXI*}

\author{
Samira Elias Silva** - Universidade de Lisboa, Portugal \\ Geovany Jessé Alexandre da Silva*** - Universidade Federal da Paraíba, Brasil
}

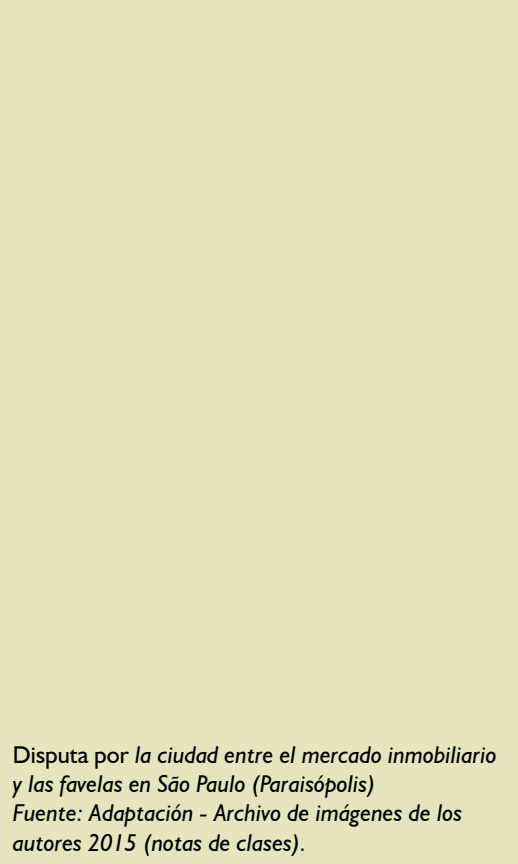

* Este artículo es el resultado de la investigación conjunta realizada por los autores dentro del campo de la planificación urbana en América Latina, desarrollado en la facultad de Arquitectura de la Universidad de Lisboa.

* Estudiante de doctorado en Urbanismo de la Facultad de Arquitectura de la Universidad de Lisboa; arquitecta y urbanista por la Universidad del Estado de Mato Grosso. Magíster en Geografía / Línea de investigación: Ambiente y desarrollo regional, Producción del espacio urbano, Desarrollo urbano, por el Programa de Posgrado PosGeo UFMT - Universidad Federal de Mato Grosso y actualmente es investigadora financiada por Capes do Brasil. Correo electrónico: samiraelias.urb@gmail.com

*** Posdoctor de la Facultad de Arquitectura de la Universidad de Lisboa; doctor e investigador por la Facultad de Arquitectura y Urbanismo de la Universidad de Brasilia - UNB-FAU; magister en Geografía por la Universidad Federal de Mato Grosso - UFMT; Arquitecto y urbanista por la Universidad Federal de Urberlândia - UFU-MG. Actualmente es profesor e investigador de Posgrado en Arquitectura y Urbanismo (PPGAU) y en Ingeniería Civil y Ambienta (PPGECAM) de la Universidad Federal de Paraíba - UFPB, Brasil. Correo electrónico: galexarq@gmail.com

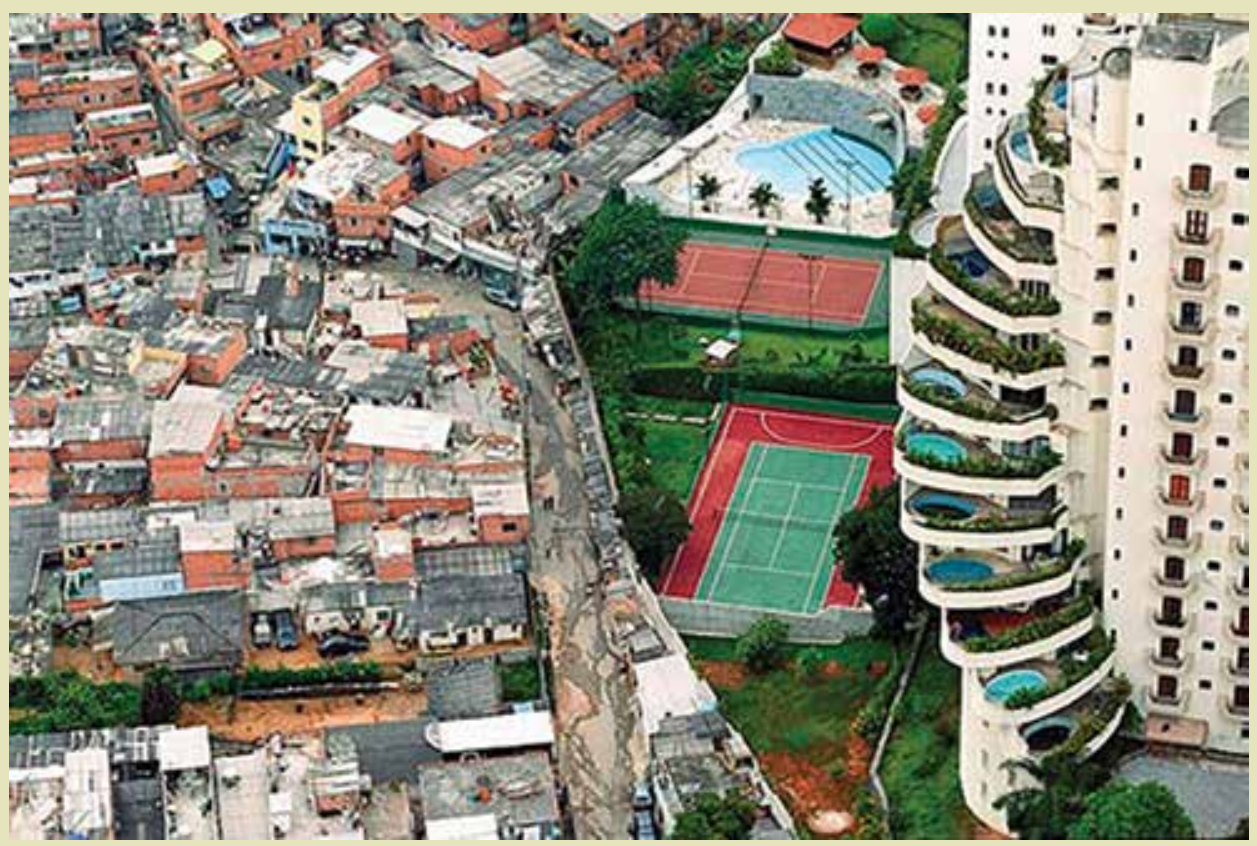

\section{RESUMEN}

En 2010 el mundo se volvió urbano: más de la mitad de la población pasó a vivir en las ciudades. Oceanía y Norteamérica superaron este límite en 1940; Europa lo alcanzó en los años cincuenta y, más tarde, Latinoamérica en la década de 1960. Sin embargo, en esta última, la urbanización un poco tardía, no estuvo acompañada por un desarrollo paralelo en el campo social y económico, ni tampoco en las políticas públicas o en la planificación territorial, situación que trajo consigo crecientes crisis urbanas que afectaron la calidad de vida, la vivienda, la salud y la movilidad, entre otros.

A partir de la identificación de la problemática mencionada y siguiendo un método investigativo exploratorio, se hizo una revisión bibliográfica, donde se consultaron datos secundarios y cartografía, de modo que al final fueron señalados algunos escenarios alternativos al proceso de explotación territorial, debido a la exacerbada valorización del suelo y de la especulación inmobiliaria, la cual se agudiza muchas veces por el transporte público deficiente, por las dificultades para acceder a los equipamientos y servicios urbanos, o inclusive por el predominio de la violencia urbana en determinadas áreas. Tales factores negativos pueden actuar como impulsadores de la especulación, y es en este punto que el presente artículo busca argumentar algunas premisas relacionadas, en especial, con aquella planificación urbana de índole económica que prioriza el automóvil y la especulación urbana.

\section{PALABRAS CLAVE}

Urbanización, América Latina, especulación inmobiliaria, movilidad, vivienda. 


\section{AMÉRICA LATINA URBANA: O HABITAT DO SÉCULO XXI}

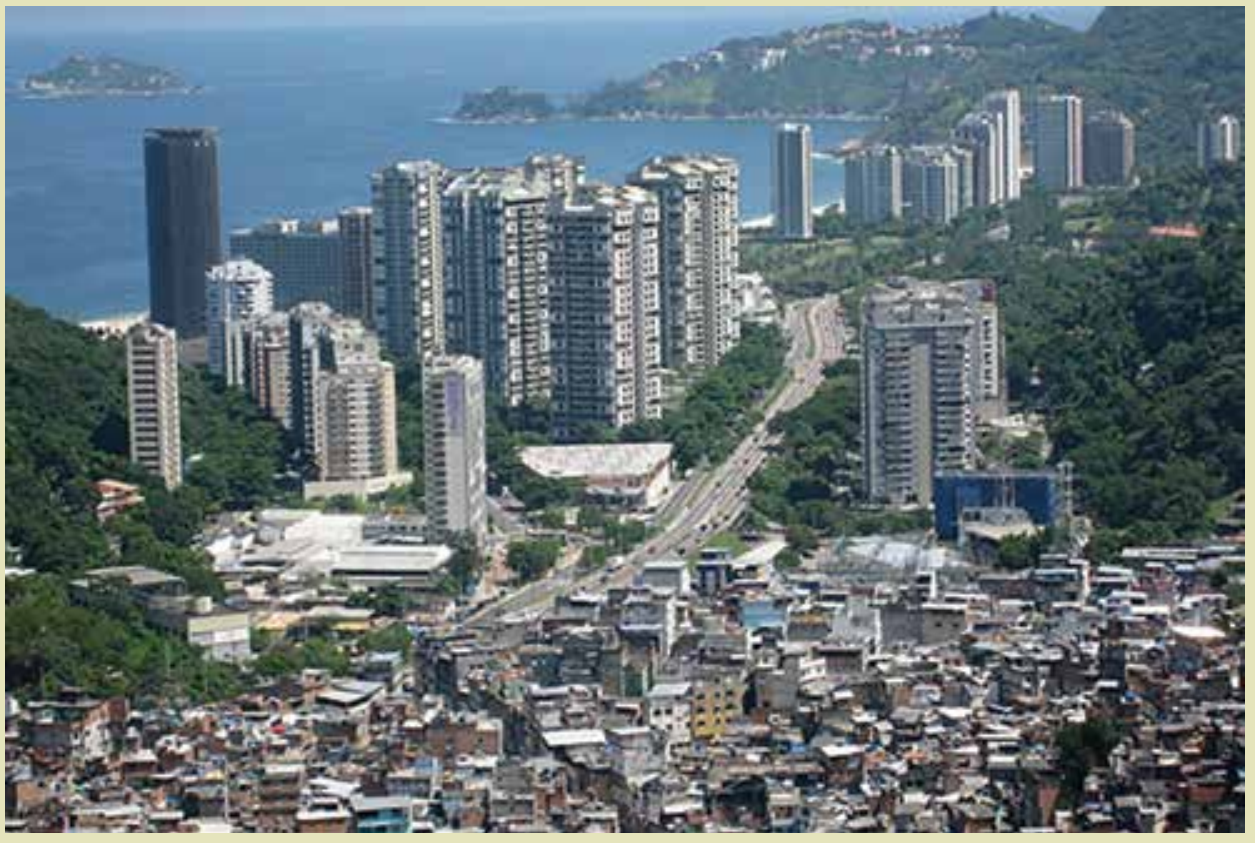

\section{RESUMO}

Em 2010 o mundo se tornou urbano, mais da metade da população passou a habitar as cidades. Se a Oceânia e a América do Norte ultrapassaram essa marca na década de 1940, a Europa atinge nos anos de 1950, e a América Latina a seguir, nos anos de 1960. Todavia, essa urbanização um pouco tardia não foi acompanhada por um desenvolvimento no campo social e econômico, assim como nas políticas públicas e no planejamento territorial, o que resultou em crescentes crises urbanas que englobam a qualidade de vida, habitação, saúde e mobilidade, dentre outros quesitos.

Para enquadramento da problemática e do método investigativo exploratório, adotouse a revisão bibliográfica, consulta a dados secundários, mapeamentos, para que ao final fossem apontados alguns cenários alternativos ao processo de exploração territorial por meio da valorização exacerbada do solo e da especulação imobiliária, esta muitas vezes potencializada pelo transporte público deficitário, pelo acesso deficitário a equipamentos e a serviços urbanos, ou mesmo pelo predomínio da violência urbana em determinadas áreas . Tais fatores negativos podem atuar como impulsionadores da especulação, e é nesse ponto que este trabalho pretende ancorar suas afirmativas, relacionadas em especial ao planejamento urbano de ênfase econômica, que prioriza o automóvel e a especulação urbana.
Disputa por la ciudad entre el mercado inmobiliario y las favelas Río de Janeiro, Rocinha

Fuente: Adaptación - Archivo de imágenes de los autores 2015 (notas de clases).

\section{PALAVRAS-CHAVE}

Urbanização, América Latina, especulação imobiliária, mobilidade, habitação. 


\section{INTRODUCCIÓN}

En la contemporaneidad la urbanización mundial presenta características distintas de las expresiones teóricas de antaño, como consecuencia de la aparición de nuevas dinámicas espaciales y territoriales, así como de la reafirmación de procesos urbanos consolidados en el pasado, especialmente desde la formación de la ciudad industrial euro-occidental. En una determinada urbe, los cambios y los problemas resultantes están presentes de distintas maneras $\mathrm{y}$, al mismo tiempo, interconectados a procesos más globales que son recurrentes y reproducibles en regiones diversas, por ejemplo, los procesos de urbanización que se iniciaron en la Europa del siglo XVIII y XIX, y que solo fueron evidenciados en América Latina a finales del siglo XIX e inicios del siglo XX (en otros casos, después de la mitad del siglo $X X$, o aun, en algunas regiones menos industrializadas del continente, tales procesos similares ni siquiera ocurrieron). Problemas en la planificación urbana, la movilidad urbana de baja eficiencia y calidad, déficit habitacional y la división territorial desigual -de la riqueza y de oportunidades-acompañan la complejidad y la dinámica de cambios de las ciudades en desarrollo, exigiendo nuevas pautas interpretativas en las políticas urbanas y nuevas estrategias transformadoras que contribuyan a una constante renovación de pensamiento en la organización, planificación y gestión de las ciudades. Si la planificación y la legislación urbana son estáticas, legalistas y tecnocráticas, las ciudades latinoamericanas presentarán un dinamismo aparte de la gestión territorial, carente de vivienda, espacios de ocio, infraestructura y equipamientos para una gran parte de la creciente población de este continente.

De esta forma, conceptos, respuestas o tecnologías urbanas que funcionan bien en otros contextos urbanos no resultan tan eficaces al momento de replicarse para las realidades urbanas latinoamericanas, dentro de las cuales convergen aspectos culturales, económicos, históricos, políticos y físico-espaciales que las vuelven muy complejas. En este contexto, la investigación científica anclada a procedimientos metodológicos probables y replicables puede proporcionar herramientas técnicas y teóricas capaces de responder eficientemente a problemáticas urbanas futuras.

En este ámbito, el presente artículo pretende contribuir a ese esfuerzo analítico, centrándose en la caracterización de la actual situación de las ciudades latinoamericanas (figura I), a fin de identificar alternativas eficientes para estas, a partir de ejemplos contemporáneos de urbanización exitosos.

Por último, el entendimiento de la cuestión urbana en América Latina, como punto principal de la investigación, busca comprender las condicionantes más importantes en la consolidación y constitución de procesos de urbanidad más cualitativos, observándose cuáles son los procesos recurrentes en países y regiones distintas, capaces de caracterizar aspectos replicables de un cierto "modelo" de urbanización latinoamericana, así como definiendo las particularidades derivadas de la cultura, de las distintas formas de apropiación de los espacios públicos, modos de hábitat y particularmente el de movilidad.

Ahora bien, se hace evidente que en países y ciudades latinoamericanas se pueden observar procesos específicos de urbanización y movilidad que generalmente no son abordados por la literatura especializada desde un punto de vista crítico que resalte los fenómenos urbanos espaciales, que en muchos casos difieren en cuanto al grado de integración espacial y accesibilidad en las regiones de un país, o con relación a países y regiones distintas en el mismo continente. 


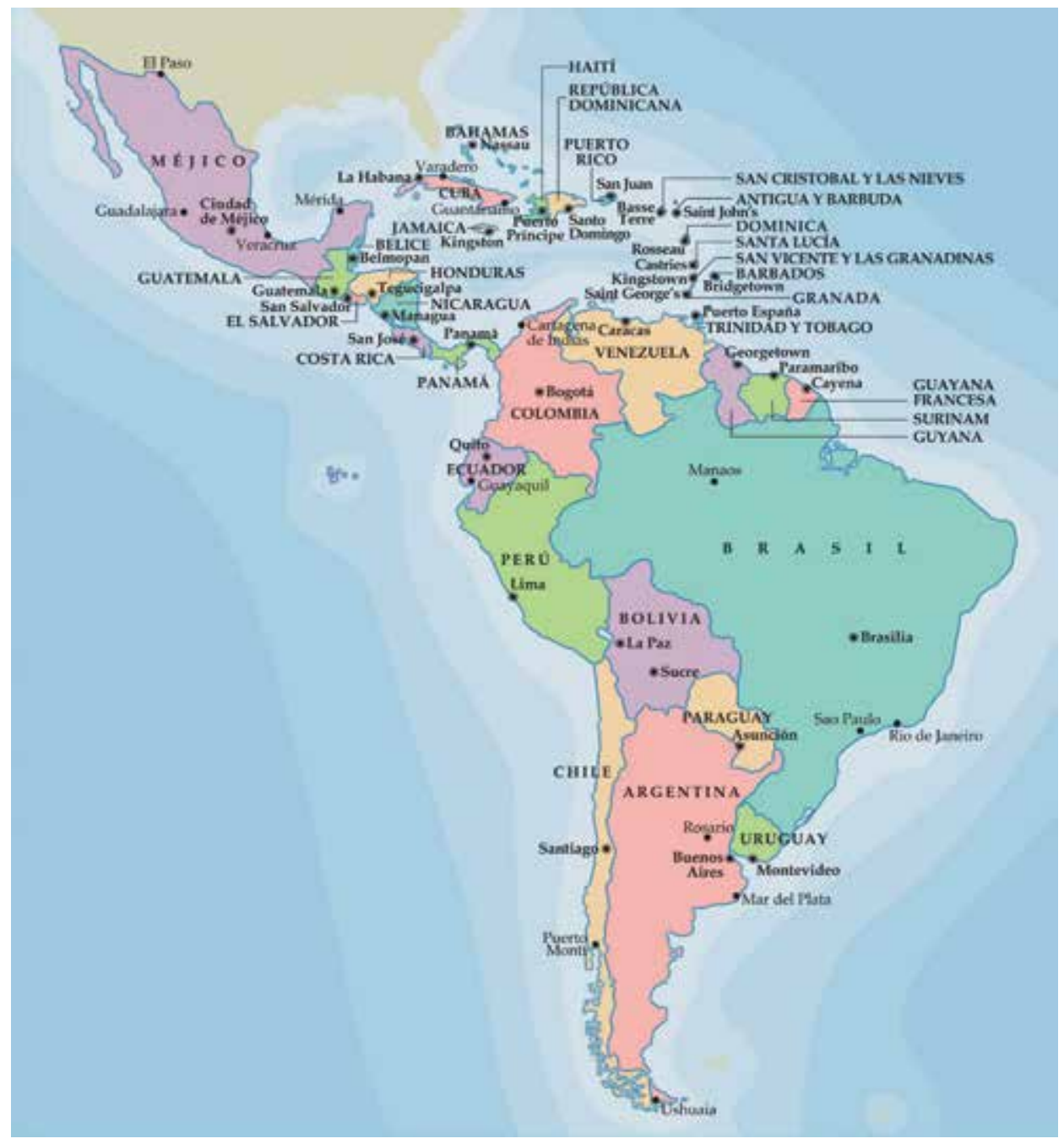

Figura I. Mapa político de América Latina Fuente: Disponible en https://aof.revues. org/6433. Acceso 23 marzo 2016.

Por otro lado, a nivel mundial el índice de urbanización superó el $50 \%$ solo hasta el 2010, Oceanía, Norteamérica y Europa ya habían superado ese límite entre los años de 1940 y 1950 (figuras 2 y 3). América Latina, a su vez, sobrepasó ese índice a mediados de la década de 1960, convirtiéndose mayoritariamente en un continente de población urbana. En América Latina, subdividida entre América Central (73\% de población urbana) y América del Sur (83\% de población urbana), se destacan por Centroamérica, México (con el $76 \%$ urbano, y la mayoría de la población del continente) y Costa Rica (76\% urbana). Por América del Sur, se tiene Uruguay (95\%), Argentina (92\% urbana), Venezuela (89\%), Chile (89\%), Brasil (85\%), Guyana Francesa (84\%), Colombia (76\%), y por último Perú (78\%). Todos por encima de la media en sus respectivos límites continentales (United Nations, 20l4).

Si tenemos en cuenta los países más urbanizados con poblaciones que superan los 10 millones de habitantes, como México, Argentina, Brasil, Chile, Colombia, Perú y Venezuela, y si se suman sus respectivas poblaciones urbanas, estas ascienden a 4 I 3 millones de personas viviendo en las ciudades, es decir, casi el $90 \%$ de toda la población urbana de América Latina se concentra en dichos lugares (figuras 4 y 5 ). 
Figura 2. Incremento de la población urbana en el mundo entre 1950 a 2050

Fuente: Elaboración de los autores (2015)

Urbanization Prospects: The 2014. con datos de Naciones Unidas. World
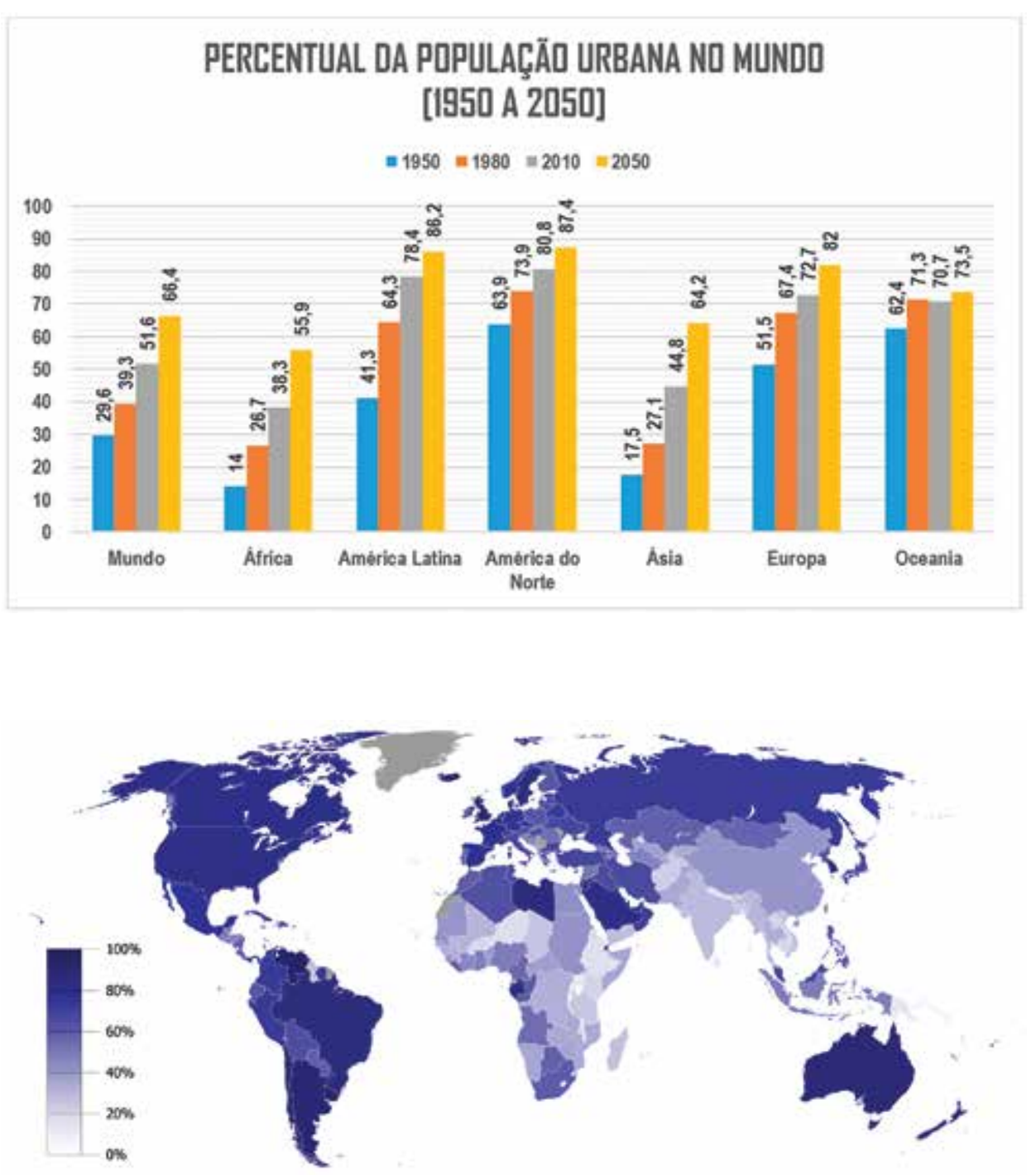

Figura 3. Mapa del porcentaje de urbanización mundial

Fuente: Disponible en: <http://smartcities. ieee.org/about.html> (20II).
Figura 4. Tasa de urbanización de países de América del Sur 1950 - 2050

Fuente: Elaboración de los autores (2015)

con datos de Naciones Unidas. World Urbanization Prospects: The 2014.

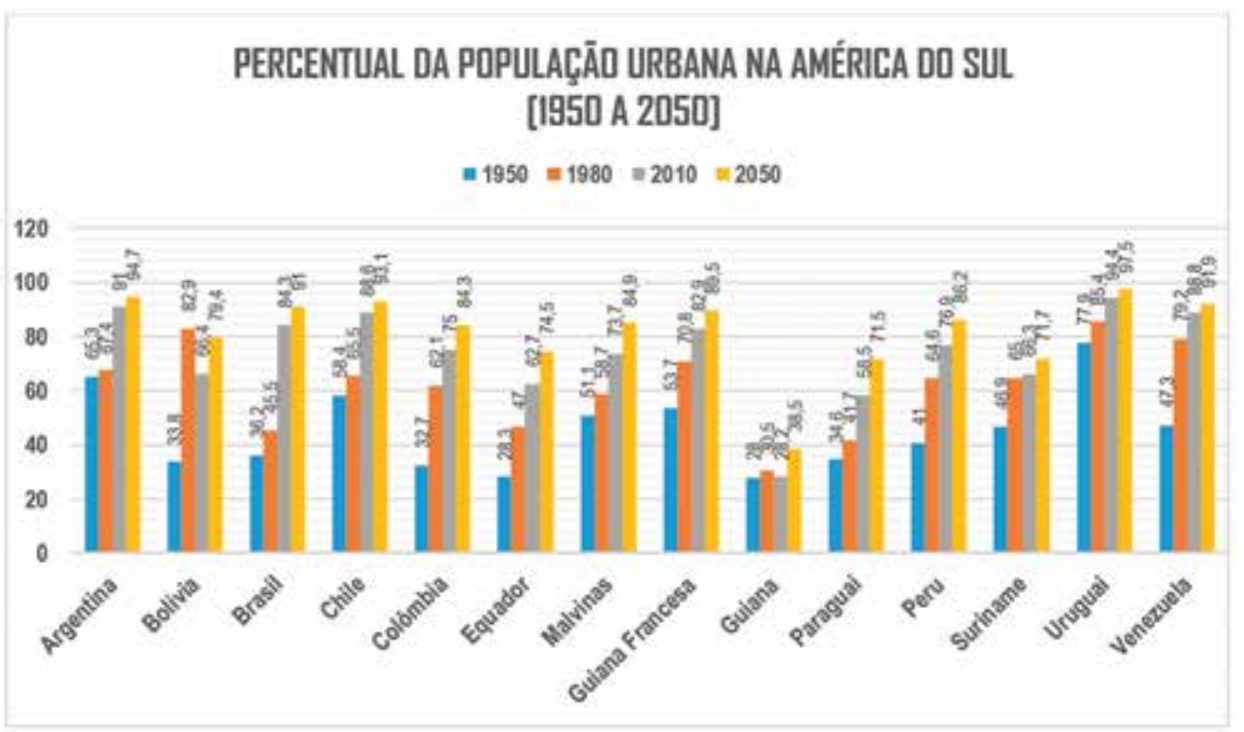




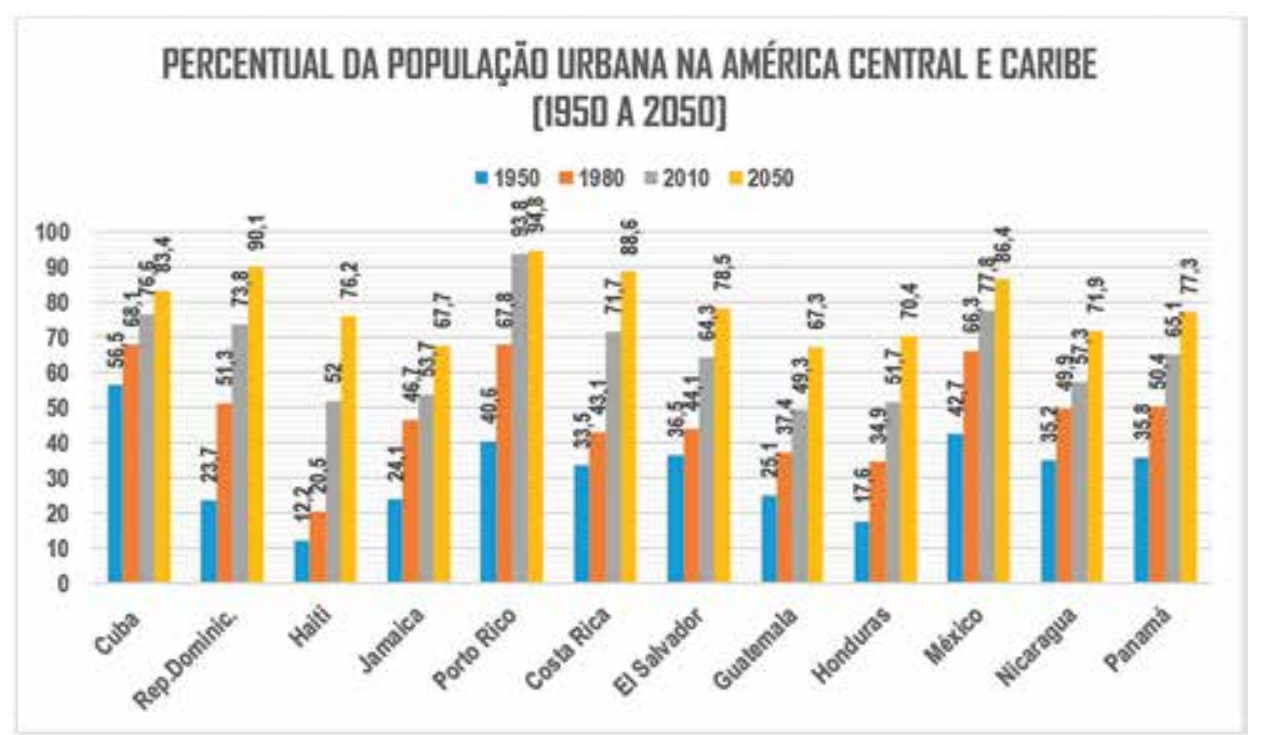

Es así como las altas tasas de urbanización que se han evidenciado durante las últimas décadas han acentuado los problemas socioespaciales en las ciudades latinoamericanas, como los conflictos relacionados con el acceso a la tierra urbana valorizada, a la vivienda, a los equipamientos y servicios urbanos deficientes a causa de la dispersión y los altos costos de vida. Se entiende que la dispersión urbana, la verticalización, así como los costos de mantenimiento de las ciudades están vinculados a la especulación inmobiliaria, a la violencia y a la movilidad, puntos que forman parte de la reflexión principal del presente artículo, el cual está dividido en dos partes. La primera parte aborda la contextualización urbana y la problemática a partir de las cuestiones habitacionales, y la segunda parte trata la cuestión de la movilidad urbana, en especial en las ciudades brasileñas.

\section{PRIMERA PARTE}

\section{CONTEXTUALIZACIÓN Y PROBLEMÁTICA URBANA: EL HÁBITAT Y LAS CIUDADES}

La urbanización latinoamericana sigue un ritmo creciente, aunque aún en desaceleración para las décadas siguientes, concentrando personas y recursos en las ciudades, algunas de ellas grandes regiones metropolitanas globales. El impacto que tuvo el crecimiento de las ciudades, especialmente en el período 1950 a 1970, permitió la recurrencia de un pensamiento urbano que buscaba encontrar marcos estructurales históricos de la formación urbana caracterizados por la dependencia, modernización y reconocimiento de la diversidad y de especificidades de los procesos de urbanización que caracterizaron los cambios de las ciudades en América Latina. De igual forma, definió el proceso de urbanización de la mayoría de las grandes ciudades actuales. Por su parte, este continente vive un momento singular que impone la reflexión sobre los paradigmas de la contemporaneidad urbana, pues, de acuerdo con el ONU Hábitat (Programa de las Naciones Unidas para los Asentamientos Humanos), la tasa de urbanización en Brasil y en los países de América del Sur llegará al $85 \%$ para 2030, siendo superior a las verificadas en el Norte de Europa (80\%) y en América del Norte (87\%). En México y en los países que forman la región andina ecuatorial la urbanización alcanzará el $85 \%$ en ese mismo período.
Figura 5. Tasa de urbanización de países de América Central y el Caribe (países con más de un millón de habitantes, excepto Trinidad y Tobago, que tienen menos del $10 \%$ de población urbana del total de habitantes), 1950 - 2050

Fuente: Elaboración de los autores (2015) con datos de Naciones Unidas. World Urbanization Prospects: The 2014. 
Figura 6. Favela en 1950 donde se ubica hoy el Parque Ibirapuera. Área no loteada de la ciudad de São Paulo, Brasil, que fue ocupada por habitantes "sin techo" de bajos ingresos Fuente: Parque Ibirapuera, SP, Brasil. Disponible en http://www.parqueibirapuera. org/wp/wp-content/uploads/2013/02/ favela I.jpg. Acesso 14 de marzo de 2016. Foto de Sebastián Assis Pereira.
En el caso de las sociedades urbanas emergentes, estas se caracterizan por la gran concentración de población en el interior de las ciudades que las conforman, en la mayoría de los casos, metrópolis regionales ( $y$ algunas de escala global) que agregan varias ciudades conurbadas. Siendo la industrialización uno de los factores más importantes que han contribuido a dicha concentración poblacional; sin embargo, los nuevos habitantes urbanos no obtuvieron un acceso igualitario a la tierra, a empleo y vivienda, lo cual trajo consigo, entre otras cosas, grandes aglomeraciones habitacionales, fragmentadas o agrupadas que ocuparon áreas periféricas y áreas de reserva que no habían sido parceladas, bien sea por ser posesión del Estado o por interés ambiental (figuras 6 y 7 ).

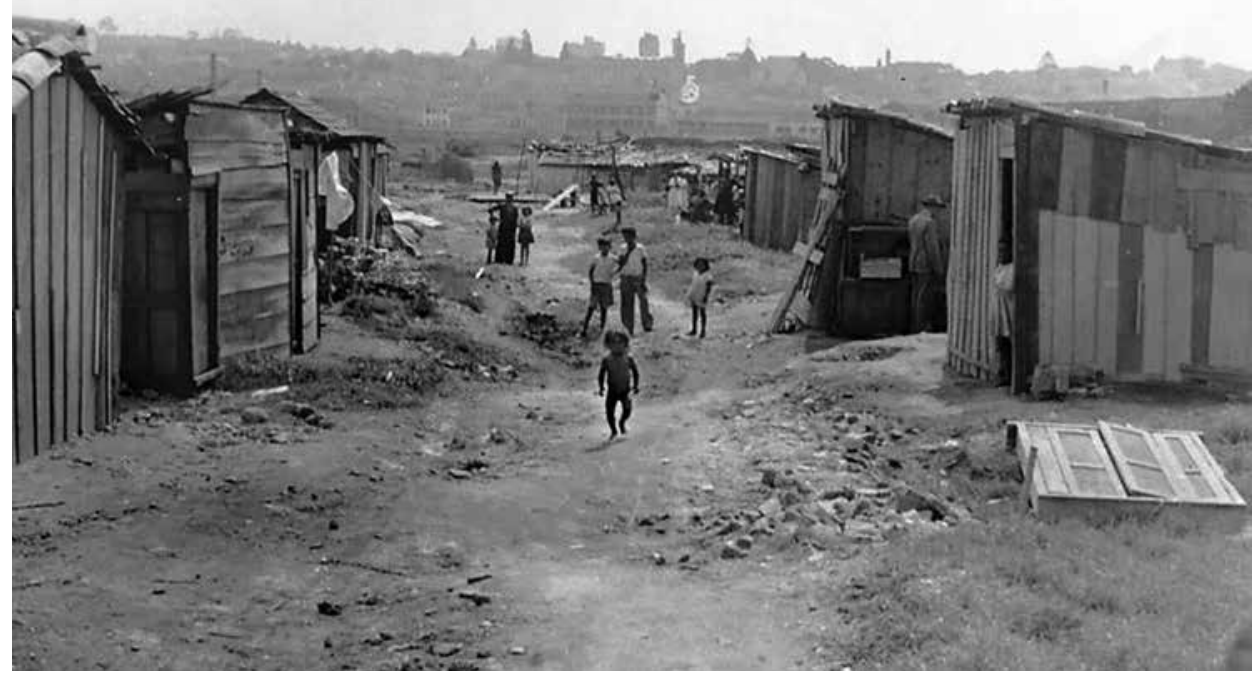

Aunque actualmente la urbanización avanza a un ritmo más lento que el identificado en el pasado, hoy el $34 \%$ de la población de América Latina vive en ciudades con más de un millón de habitantes. Este cuadro indica que los países ingresaron en el modelo de sociedades urbanas, pero con ciudades improvisadas con poca planificación. Aun así, algunos países invirtieron en políticas urbanas y habitacionales regulatorias con el fin de promover el bienestar colectivo, las cuales no siempre respondieron a las demandas de los sectores más necesitados.

Según informaciones del BID (20I2), una de cada tres familias en América Latina y el Caribe no posee una vivienda adecuada. Es decir que, aproximadamente 59 millones de personas están relegadas a ocupar viviendas en áreas de riesgo, improvisadas, sin servicios básicos de saneamiento o calidad urbana compatible. Más de la mitad de las familias que viven en las $4 \mathrm{I}$ principales ciudades de la región no poseen medios para la adquisición de viviendas, lo que evidencia uno de los obstáculos más difíciles que deben sortear los países latinoamericanos al momento de generar e implementar políticas habitacionales inclusivas, a lo que se suma la poca organización institucional, las carencias técnicas y tecnológicas, así como el déficit presupuestal que muchos de estos países presentan.

En el caso de Bolivia, especificamente en la ciudad de La Paz cerca del 7। \% de las familias no tiene condiciones financieras para adquirir casa propia. En Santa Cruz el porcentaje sube al $72 \%$. En Venezuela, en la ciudad de Caracas, se sitúa en el $80 \%$. En los demás países estudiados por el BID el porcentaje varía entre el $60 \%$ a $30 \%$. La ciudad que se muestra más favorable para la adquisición de una vivienda de calidad es San José, donde solo el $29 \%$ de las familias no tiene los recursos económicos para la adquisición de una casa propia. 


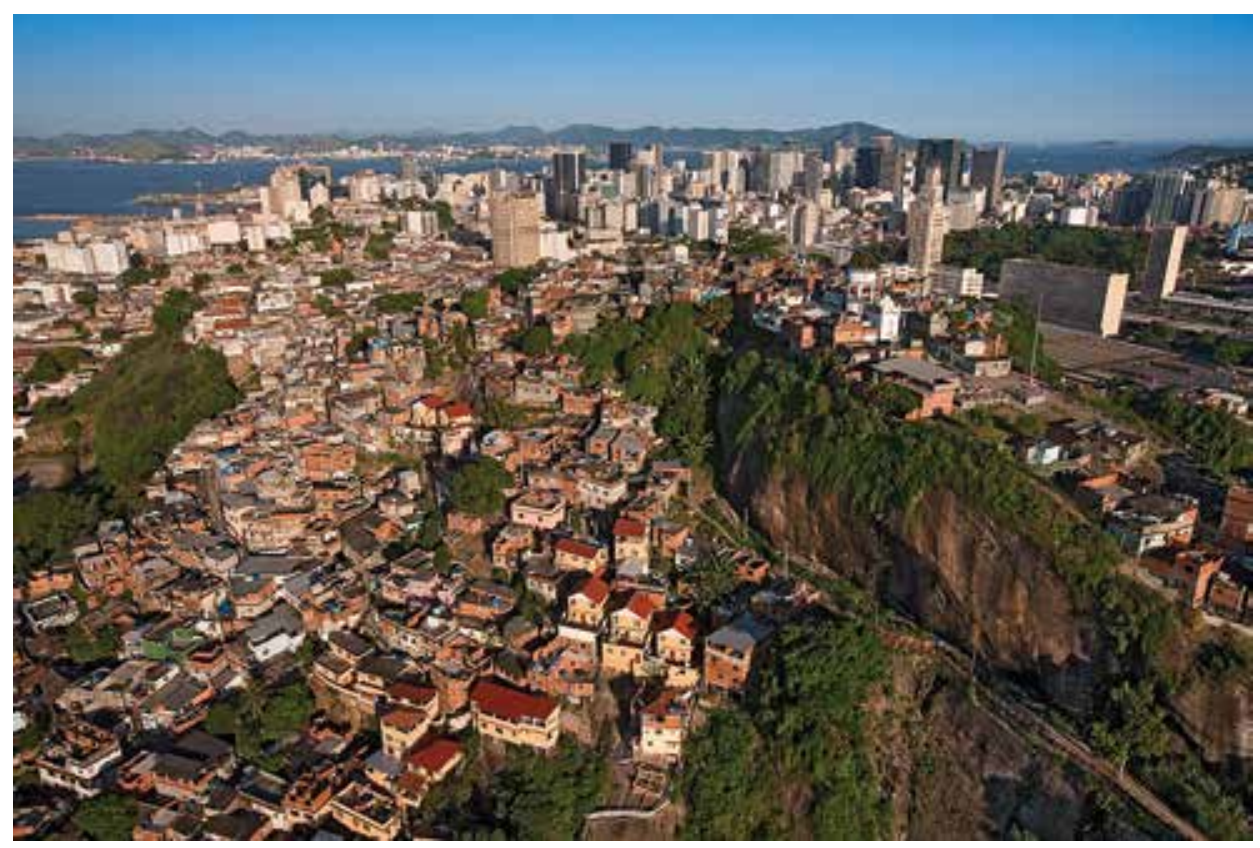

El estudio del BID apunta a que las disparidades en las condiciones de acceso a la vivienda en América Latina y el Caribe son muy diversas, en el caso de los países más poblados como Brasil, México, Colombia y Argentina un I/3 de la población, es decir, unos I 35 millones de personas aproximadamente habitan en casas con condiciones precarias, mientras que otros como Nicaragua (78\%), Bolivia (75\%), Perú $(72 \%)$ y Guatemala $(67 \%)$ se encuentran en situaciones bastante críticas, con la mayoría de su población en viviendas descalificadas. El país en mejor condición en este aspecto es Costa Rica (18\%), seguido de Chile (23\%), Uruguay (26\%) y Venezuela (29\%), respectivamente (figura 8 ).

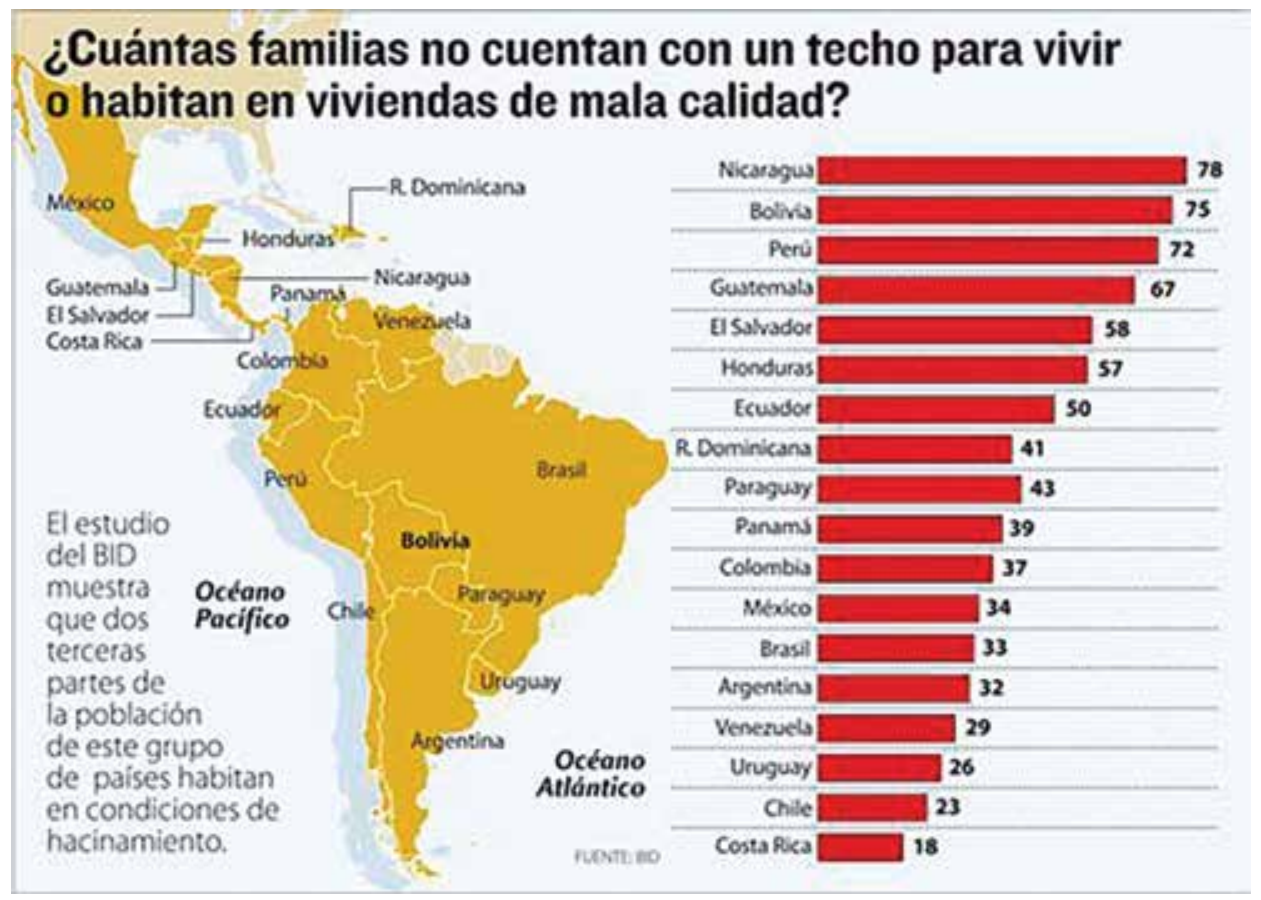

Figura 7. Favela de Providência en Rio de Janeiro, Brasil. Ejemplo de área de preservación ambiental que fue ocupada de forma irregular por la población, más pobre de la ciudad

Fuente: Yann Arthus Bertrand (2009)
Figura 8. En América Latina I/3 de las familias no tienen una vivienda adecuada Fuente: BID (20/2). Disponible en http:// www.iadb.org/es/noticias/comunicados-deprensa/2012-05-14/deficit-de-vivienda-enamerica-latina-y-el-caribe,9978. Acesso 23 de marzo 2016. 
Así mismo, es importante señalar al respecto de este tema, que México es un caso particular, pues siendo un país con más de 100 millones de habitantes, tiene un déficit habitacional bastante elevado que asciende a 15 millones de unidades aproximadamente, según informaciones del programa federal Infonavit (Instituto del Fondo Nacional de la Vivienda para los Trabajadores, fundado en 1972). Sin embargo, a pesar de la dimensión de la demanda atendida por dicho programa estatal, los casos de abandono de las viviendas otorgadas a la población son preocupantes, pues las virtudes y problemas se asemejan mucho a los conflictos presentes en otros países de América Latina, como Brasil, el cual tiene un programa similar de vivienda. En la figura 9 se puede observar en la fotografía superior los nuevos conjuntos de vivienda en serie mexicanos generados por su programa habitacional estatal, y en las fotografías inferiores las casas abandonadas debido a los altos costos y endeudamiento bancario de las familias, la violencia e incluso las largas distancias a los puestos de trabajo.

En Brasil, el Programa Federal Minha Casa Minha Vida (MCMV) ha atendido desde el año 2009 miles de familias, siendo propuestas aproximadamente 3,5 millones de viviendas (de las cuales se han entregado aproximadamente 2 millones hasta 20 I4), con un costo que se sitúa por encima de los 100.000 millones de dólares, según el Ministerio de las Ciudades (20I5). Aun así, hoy se calcula que el déficit de vivienda en el país se sitúa en 5,8 millones de viviendas. El programa, a pesar del alcance, ha enfrentado críticas en cuanto al modelo que heredó del período militar, en el cual el BNH (Banco Nacional de la Vivienda) implementó entre 1960 y 1980 alrededor de 4,3 millones de unidades de vivienda que debieron hacerle frente al aislamiento de dichas comunidades respecto a las áreas centrales del resto de la ciudad, así como la distancia hacia las zonas de trabajo, la ausencia de equipamientos urbanos, la baja calidad constructiva de las viviendas enmarcadas dentro de una arquitectura y un desarrollo urbano estandarizado y obsoleto (figura 10). Otra crítica importante al modelo BNH-MCMV es el énfasis en el mercado (construcción civil, bancos) y la especulación del suelo urbano, sin tener en cuenta que cada familia se endeudó por 25 años o más, viviendo en barrios aislados, mientras que otras zonas de la ciudad se "valorizaban"y eran dotadas de infraestructura, condiciones inaccesibles a los programas de vivienda social y sin ningún control a la especulación.

\section{SEGUNDA PARTE}

\section{EL ESCENARIO URBANO BRASILEÑO Y LAS CUESTIONES DE MOVILIDAD}

El proceso de urbanización en Brasil es reciente y, a pesar de que la industrialización se inició a fines del siglo XIX, el crecimiento poblacional en las ciudades solo se aceleró en la segunda mitad del siglo XX, y fue a partir de la década de 1960 que la población urbana superó la rural. La particularidad del caso brasileño se dio como consecuencia de la velocidad del proceso de urbanización a partir de entonces, siendo esta muy superior a la de los países capitalistas más ricos durante el mismo período. Ya para la segunda mitad del siglo XX, la población urbana brasileña pasó de 19 millones a 138 millones, multiplicándose 7,3 veces, con una tasa media anual de crecimiento del $4,1 \%$. Durante la última mitad del siglo pasado, cada año en promedio 2,4 millones de habitantes eran añadidos a la población urbana del país (figuras II y I2).

Este acelerado proceso de urbanización generó transformaciones estructurales que impactaron tanto la sociedad como la economía brasileña. De hecho, era la propia sociedad brasileña, rural y provinciana, la que se transformaba cada vez más en urbana y 

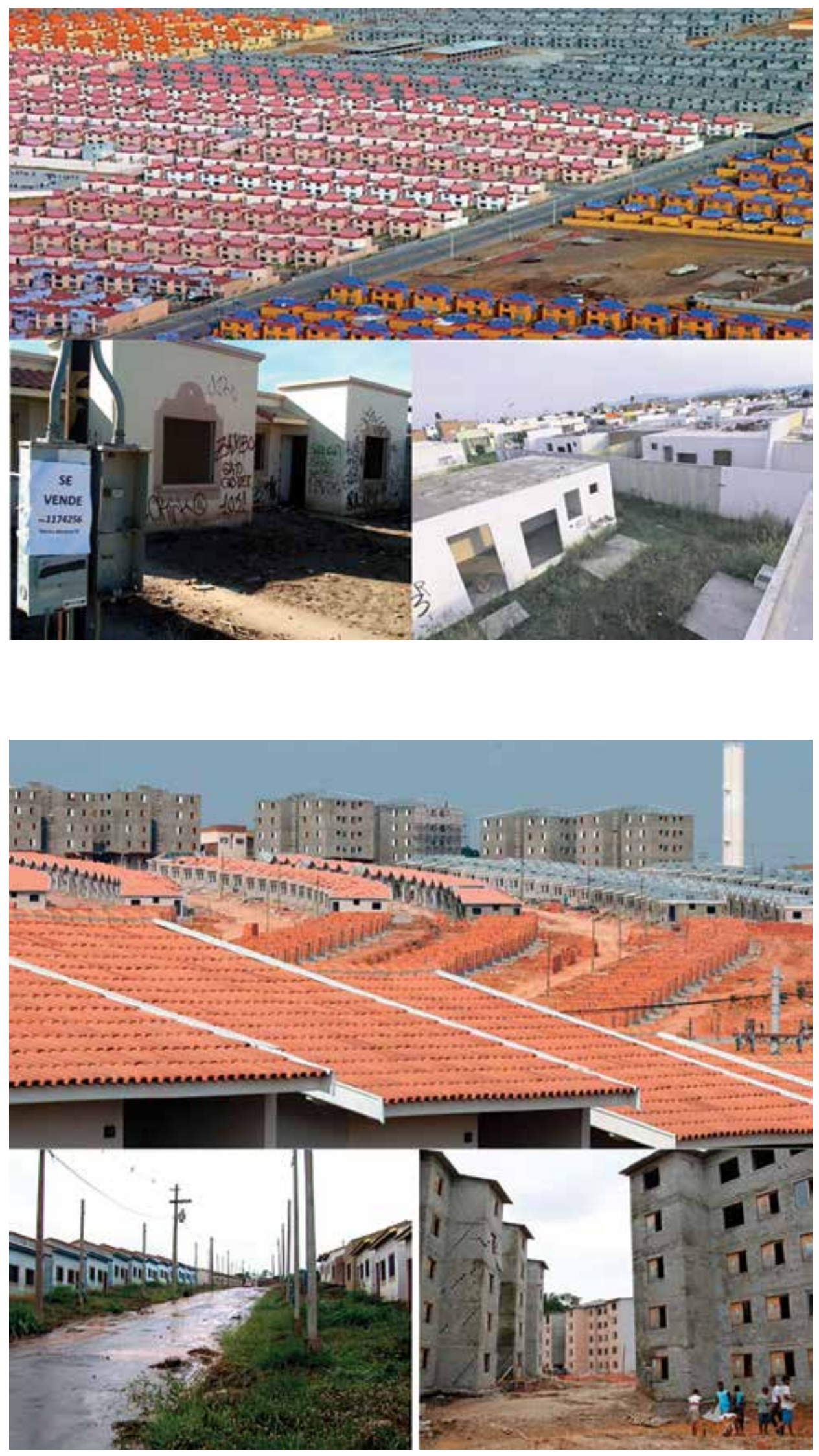

Figura 9. Conjuntos de vivienda en serie del programa habitacional mexicano

Fuente: Disponible en <www.informador. com. $m x>$. Acceso 23 de marzo 2016.
Figura 10. Programas habitacionales Minha Casa Minha Vida (MCMV) en Brasil Fuente: Disponible en <http://www. diariodecanoas.com.br/> Acceso 23 de marzo 2016. 
Figura II. Favela Morro do Pinto, Rio de Janeiro (19/2)

Fuente: Disponible en http://nuevomundo revues.org/50103 Acceso 23 de marzo de 2016. Foto de Augusto Malta.

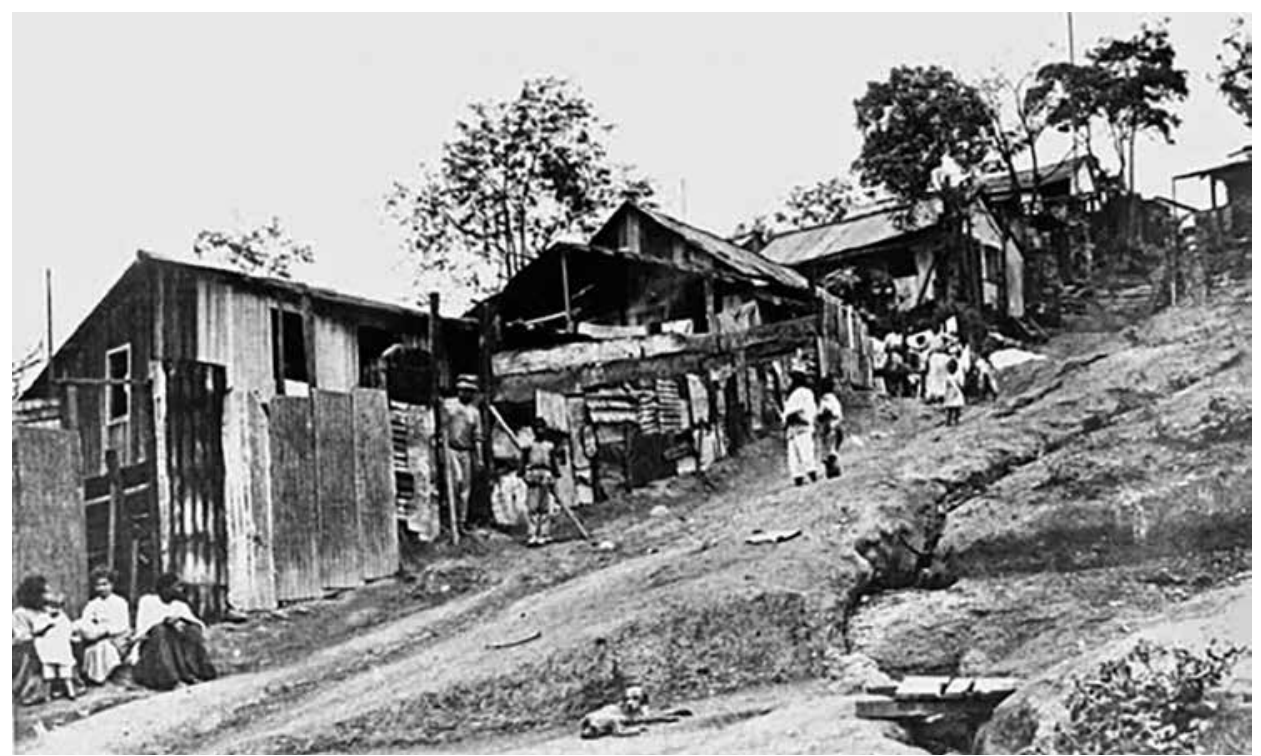

Figura 12. Imagen de la favela del Capanema en Curitiba-PR, Brasil, en la década de 1970 Fuente: Fotografía del periódico Gazeta do Povo (2015)

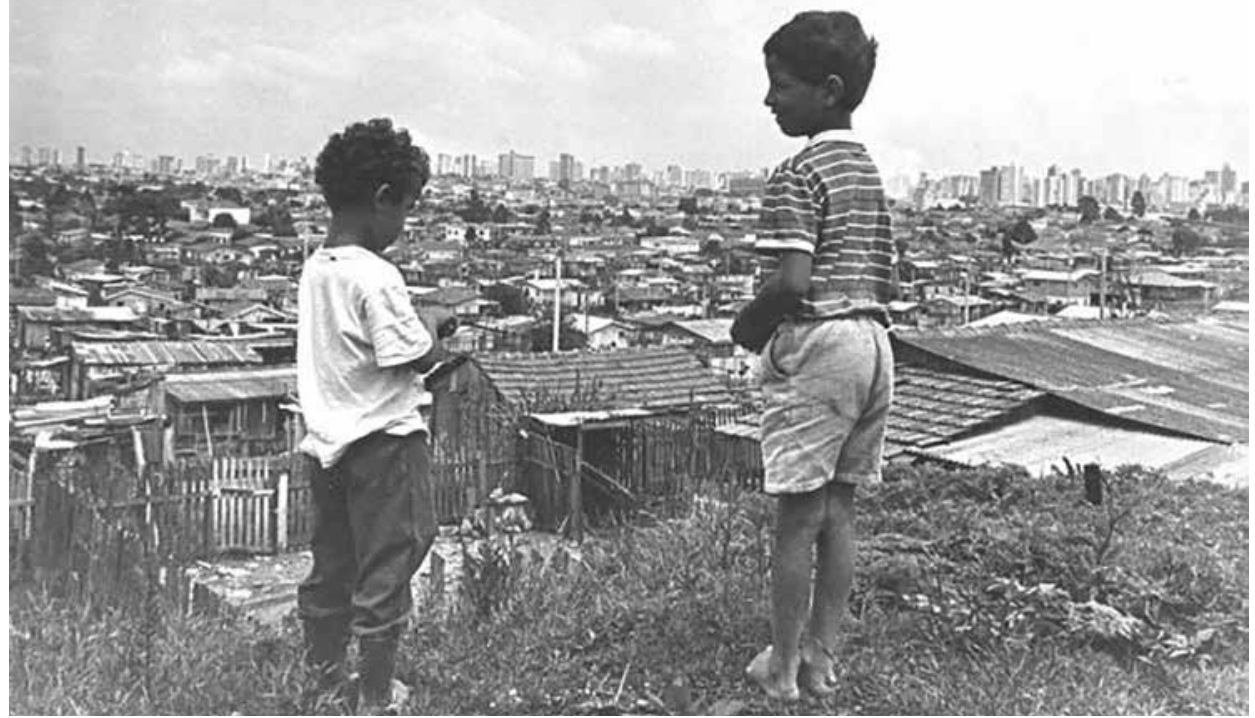

moderna, haciendo irreversible esa prioridad ciudadana y difundiendo nuevos patrones de relaciones sociales -incluso las relaciones de producción-y nuevos estilos de vida, modos de habitar, consumir y desplazarse en el territorio. Un Brasil moderno, urbano-industrial, que se superponía al Brasil arcaico, generando un modelo de desarrollo económico y social con fuertes desequilibrios regionales y sociales.

En este punto se hace necesario abordar la historia nacional y reflexionar sobre el papel de las migraciones internas dentro del proceso de urbanización en el país. Estas fueron decisivas para integrar territorialmente a la sociedad brasileña durante la segunda mitad del siglo XX. Con la expansión de los sistemas de transporte y comunicación urbanos, los migrantes circularon aceleradamente, contribuyendo a la estructuración de un sistema de ciudades de dimensión nacional, liderado por las grandes aglomeraciones metropolitanas. Los flujos migratorios, que contribuían a consolidar el sistema de ciudades, se intensificaron con el desarrollo de la economía y la sociedad entre las décadas de 1950 y 1980. La tradición migratoria, enraizada en la cultura brasileña, abría la perspectiva de articular la 
movilidad espacial con la movilidad social. Sin embargo, independientemente de las causas del crecimiento descontrolado de las ciudades brasileñas, en ellas se ha evidenciado una crisis de movilidad, que se ha deteriorado día tras día, mientras los índices de movilidad poblacional en zonas metropolitanas de baja renta se ha visto reducido.

Es por ello que en Brasil, uno de los grandes desafíos de las ciudades es la movilidad urbana, pues el desplazamiento colectivo e individual pasa por cambios constantes, y las políticas públicas están siendo ineficaces frente a estos. Bajo la mirada de Nunes da Silva (20l3), por un lado, la industria automovilística es uno de los motores más importantes de la nueva industria, contribuyendo a la modernización del tejido productivo del país, sin embargo, por otro lado, las elites y clases medias de la sociedad no conciben otro tipo de movilidad que no sea la basada en el transporte individual, lo que ha incrementado el caos vehicular dentro de las ciudades al poner sobre las vías un alto número de automotores. Ahora bien, dicha preferencia por el transporte individual no solo se trata de una cuestión de estatus y prestigio social, también se ve influenciada por la falta de flexibilidad y capacidad de respuesta del sistema de transportes colectivos públicos, el cual no puede asegurar las condiciones de confort que le permita competir con el transporte individual, constituyéndose así un choque entre la realidad del sistema vial inadecuado y la demanda desenfrenada por el servicio. Dentro de este panorama, las regiones metropolitanas son, sin lugar a dudas, las que más sufren con las consecuencias del crecimiento acelerado y desordenado de la ciudad, así como por el deterioro de la movilidad en su interior, constituyéndose en un desafío diario el proporcionarles transporte de calidad a sus habitantes, el cual facilitaría el acceso permanente a las diversas actividades urbanas.

Las dificultades de afrontar los problemas ligados a la movilidad urbana en países de América Latina radican en intentar imponer en dichos países las mismas estrategias que se están practicando actualmente en los países donde las diferencias sociales y económicas no son tan intensas, $y$ donde la conciencia colectiva de sus impactos propicia el desarrollo de políticas de movilidad más equilibradas y más atentas a los problemas medioambientales y a la cohesión social. Se deben considerar entonces diferencias en la aplicación de estrategias, cuando se trata de países desarrollados y países emergentes, evaluando sobre todo las especificidades de la participación social, las características socioculturales y ambientales, la estructura económica y la organización del espacio urbano para llegar a un modelo equilibrado.

La caótica situación de los transportes urbanos, especialmente en las metrópolis brasileñas y latinoamericanas, evidencia una caída constante del índice de movilidad colectiva de la población y el crecimiento de la tasa de auto-motorización, con la preponderancia del transporte individual sobre el transporte colectivo. Por su parte, la distribución de los modales motorizados indica la destacada importancia que asume el autobús como transporte de masa, teniendo en cuenta la suspensión, déficit o insuficiencia de las inversiones estatales en ferrocarriles o metro.

Uno de los sistemas de transporte masivo más conocidos, es el modelo de transporte colectivo BRT (Bus Rapid Transit), que fue creado en Brasil en la década de 1970, en Curitiba, ya bastante difundido en el país y en otras regiones y ciudades del mundo, tales como Bogotá, Medellín, Pekín, Santiago, Estambul, Ciudad de México, Boston, París. Otras alternativas como VLT - Veículo Leve sobre Trilhos (Tren Ligero o LRT - Light Rail Transit en inglés) se están implantando en el país, pero muchos proyectos ideados para la Copa de 2014, todavía se encuentran en construcción, incluso después del evento de la FIFA. 
En las regiones metropolitanas brasileñas, la movilidad apenas llega al 60\% del promedio mundial. El tiempo de desplazamiento residencia-trabajo-residencia ha aumentado significativamente. La proporción de habitantes / vehículo en São Paulo, por ejemplo, pasó en 20 años (1977/97) de 6 x I a 2 x I. La velocidad media de los autobuses en 10 años bajó de 22 a 15 kilómetros por hora (Agenda 21 , 2000).

Es decir, la tasa de motorización en el país pasó de 72 habitantes / automóvil en 1960, para poco más de cinco en 1998 y llegando a 4,3 en 2005. La cantidad media diaria de viajes por habitante tiende a subir de I,5 en 1995, para I,7 en 2005 (Agenda 2 I, 2000).

En el caso de los modales motorizados de transporte, estos son reconocidos como una de las principales fuentes de contaminación del aire en las ciudades, llegando a comprometer la salud pública debido a la dispersión de los gases producidos por estos y la expulsión del material particulado, el cual resulta muy perjudicial por la incidencia de los vientos. De acuerdo con los estudios realizados bajo el patrocinio del Banco Mundial, el $20 \%$ de los contaminantes en la atmósfera de la Región Metropolitana de Río de Janeiro son responsabilidad del transporte.

Considerando el Plan Nacional de Movilidad Urbana, aprobado en enero del 2012 en Brasil, se determinaron una serie de acciones para ser realizadas por todas las esferas del Gobierno. Actualmente, I 720 municipios brasileños con características y especificidades distintas están obligados a cumplir un mismo plan nacional de movilidad, y ciertamente esa burocracia equivocada e inadecuada va a generar dificultades durante la ejecución de cualquier mejora propuesta para determinados modales de movilidad.

En un contexto más específico y esclarecedor para ese trabajo, es importante preguntarse sobre la relevancia de explicar el significado de la palabra movilidad. Por eso, debatir la movilidad urbana como una política pública es asociar las acciones integradas e integradoras que establecen reglas y normas para el uso del suelo, los transportes públicos motorizados y los medios de transporte no motorizados. Vasconcelos (1996) define que la movilidad es un atributo asociado a las personas y a los bienes, correspondiente a las diferentes respuestas dadas por individuos y agentes económicos a sus necesidades de desplazamiento, consideradas las dimensiones del espacio urbano y la complejidad de las actividades desarrolladas en él. Por lo tanto, es importante pensar en la producción de la ciudad, incluyendo la preocupación de crear condiciones básicas de movilidad para que haya buena calidad de vida urbana, pero partiendo de las especificidades de cada ciudad con el fin de proponer un plan específico acorde a la realidad local.

La movilidad proporcionada por el transporte público facilita el perfeccionamiento profesional continuo de las personas, el ocio, el acceso a equipos de salud, centros culturales, entre otros, sin embargo, en Brasil, este escenario se da en un ambiente construido de manera desarticulada, considerando que existen acuerdos de poder locales y regionales que favorecen la expansión urbana dispersa, protegiendo la producción y la especulación inmobiliaria. Entre otros factores, esto se debe a la ausencia o desestructuración de los órganos de planificación y gestión de transportes urbanos federales y estatales; a la formación de una estructura conservadora de poder con una fuerte capacidad de persuasión, y a la fuerza histórica de las clases y fracciones de clases ligadas a los negocios de tierra rural y urbana, presentes en pactos de poder a diferentes escalas. 
Estas transformaciones que están experimentando las ciudades contemporáneas configuran nuevos modelos. La ciudad brasileña de Florianópolis, en el estado de Santa Catarina (sur del país) por ejemplo, está inserta dentro de un contexto urbano preocupante debido a la fragmentación espacial de sus partes. La ciudad, por tener una configuración de malla urbana dispersa, fragmentada, poco conectada y poco compacta, sumado a la inadecuada e ineficiente infraestructura urbana, ha presentado grandes problemas de desplazamiento pendular. El resultado de esta situación se evidencia en los congestionamientos extensivos, la contaminación e insostenibilidad del sistema de movilidad, lo cual debería llevar a una reflexión y posterior acción sobre el uso del tiempo y del espacio en la ciudad. En el 2009, un estudio realizado a partir de un convenio firmado entre la UFSC, el Laboratorio de Sistemas de Transporte de la UFRGS y el Instituto de Planificación de Florianópolis - IPUF ya demostraba que más de 38 vías de la capital operaban con puntos de flujo de vehículos próximos a alcanzar el tope de su capacidad en las horas pico. Incluso con la implementación de algunos cambios estructurales sugeridos por el IPUF, como la ampliación de avenidas o construcción de túneles, muchos problemas no podrán ser solucionados. Pero el nuevo modelo prioriza el transporte automotor privado, lo que se refleja en el espacio cedido a esta forma de transporte, es decir, calles cada vez más amplias para estos vehículos en detrimento del espacio para el peatón, el ciclista y el transporte público. Es por ello que se debe pensar en estrategias que combinen tecnologías modales, con el proceso de planificación y diseño urbano, e incluso tengan en cuenta la cultura de desplazamiento de las personas por medios alternativos (siempre que la ciudad tenga seguridad, infraestructura y densidad poblacional para ello).

Esta realidad es producto de un descompás en las políticas públicas: aumento de la renta y del crédito para la adquisición de vehículos individuales privados, sin una correspondiente política efectiva que imprima competitividad y eficiencia para el transporte público, que están por debajo de las necesidades de los sectores productivos y sociales. A pesar de que todos estos problemas son concretos, esa percepción solo se da porque la clase media, expandida en los últimos años, es la que más fue alcanzada en esta nueva fase de desarrollo económico y, sobre todo, social en Brasil, y así discerniendo la percepción de esos problemas de forma efectiva. $Y$ ese es el escenario para la mayoría de las grandes y medianas ciudades brasileñas.

Considerando la dimensión del problema brasileño, surge la pregunta: icómo se podría proceder para mejorar la movilidad urbana en cuestión?

La esencia del problema, aunque ejerce una influencia considerable en cuanto a los modos de transporte o la combinación de modos de transporte, es, por lo tanto, cuestionarse sobre la inercia ejercida por la organización y la planificación del espacio bajo la égida de la formación social de que se trata. Por lo tanto, operar en un espacio organizado, con densidades urbanas y contenido social adecuados para cada tipo de modo y modal escogido, refuerza que esta es cada vez más la gran dificultad de las ciudades brasileñas con buena planificación urbana, pero con escala regional y federal inertes. Aplicar en su plenitud la Ley de Movilidad Urbana (Ley Federal n. 12.587 / 20 I2) y sus directrices dependerá de la superación de una serie de obstáculos urbanos, como: la especulación urbana que se mantiene en áreas intersticiales extensas; los procesos de urbanización dispersa; los mecanismos de excepción de los planes directores (y la no aplicación de muchas herramientas reguladoras del uso y ocupación del suelo urbano frente a los intereses elitistas); y las dificultades en términos de costos públicos para expropiaciones, entre otros factores. Teniendo en cuenta 
lo anterior, podríamos decir que las fuerzas de urbanización dispersa pueden derivarse de la especulación inmobiliaria por parte de los propietarios de tierras urbanas, generando una expulsión de las poblaciones más pobres hacia las áreas periurbanas de las ciudades.

Aún así, y a pesar de los obstáculos mencionados encontramos un ejemplo, que ha sido presentado como un modelo urbano, tanto para países desarrollados como para aquellos que están en via de serlo; dicho ejemplo es la ciudad de Curitiba, capital del Paraná, ubicada al sur del país. De acuerdo con el exalcalde CássioTaniguchi, el sistema de transporte urbano incentiva el desarrollo residencial y de negocios, armonizándose con los planes urbanísticos y la zonificación de la ciudad. En 1973, el Instituto de Investigaciones y de Planificación Urbana de Curitiba - IPPUC desarrolló autobuses especiales diseñados para el transporte masivo de pasajeros. Posteriormente estos se fueron adaptando y ampliando con el fin de responder al crecimiento de las necesidades poblacionales entre los años 1980 y 1990. En la actualidad el sistema transporta dos millones de personas al día. Es importante mencionar que la red de transporte proporciona cuatro alternativas modales de transporte integrados dentro de los 12 municipios que componen la región metropolitana de Curitiba. El uso masivo del sistema de transporte público en esta ciudad redujo el número de vehículos que circulan por las calles, disminuyendo los niveles de contaminación del aire, la incidencia de smog (humo y niebla), y reduciendo los riesgos de enfermedades respiratorias en la población, convirtiéndose en la primera ciudad en Brasil en utilizar combustible menos contaminante, lo que ha disminuido en más del $43 \%$ las emisiones de partículas atmosféricas.

Sin embargo, y más allá del caso exitoso de Curitiba, para el 2000, varias ciudades brasileñas presenciaron conflictos y protestas aisladas de usuarios del transporte público, entre los que se encontraban estudiantes y trabajadores, contra la baja calidad y aumentos de las tarifas de los autobuses. Así, en enero de 2005 se constituyó el Movimiento Passe Libre, en Porto Alegre, Estado del Rio Grande do Sul, con el objetivo de integrar a los usuarios y dar a conocer las reivindicaciones a escala nacional que se estaban proponiendo, utilizando los medios sociales como el Internet para la divulgación y promoción de las acciones colectivas que a lo largo de la década lograron concesiones en diversas ciudades del país, incluso teniendo en cuenta que el sector del transporte público se caracteriza por ser un mercado bastante cerrado y cargado de licitaciones públicas con informacion poco accesible y más para la población civil.

Para el 2013, Brasil tuvo una figuración importante dentro del panorama internacional debido, por un lado, a la Copa de las Confederaciones de Fútbol por realizarse en el país y, por el otro lado, gracias al Movimiento Pase Libre, el cual estaba ganando más fuerza social después de una serie de aumentos en las tarifas de los autobuses en varias capitales brasileñas, que culminaron con un número significativo de manifestaciones y revueltas, algunas con violentas represiones policiales. Aun así, dichas manifestaciones ganaron elementos de reivindicación que fueron agregados a la agenda nacional, cuestionándose entre otras cosas, sobre los altos gastos de dinero público para la Copa del Mundo, la corrupción, la violencia, los servicios precarios de educación y salud.

Ahora bien, a partir de la promesa de promover la reforma urbana en São Paulo, y presionado por la manifestación popular, el alcalde Fernando Haddad (exministro de Educación del Gobierno Federal) inicia una serie de acciones que van desde la reformulación de la legislación urbana (insertando principios de compactación y mayor densidad urbana, haciendo énfasis en la movilidad colectiva, control de la especulación y vacíos urbanos, entre otros), hasta inversiones más puntuales y estratégicas en la capital paulista. Como ejemplo, en el 2014 el Ayuntamiento de São Paulo anunció la creación de un sistema de 
ciclovías (en lugar de las plazas de estacionamientos en las calles) en varias vías colectoras y arteriales de la ciudad, así como la definición de nuevos corredores viales para el uso exclusivo de los autobuses (figura 13).
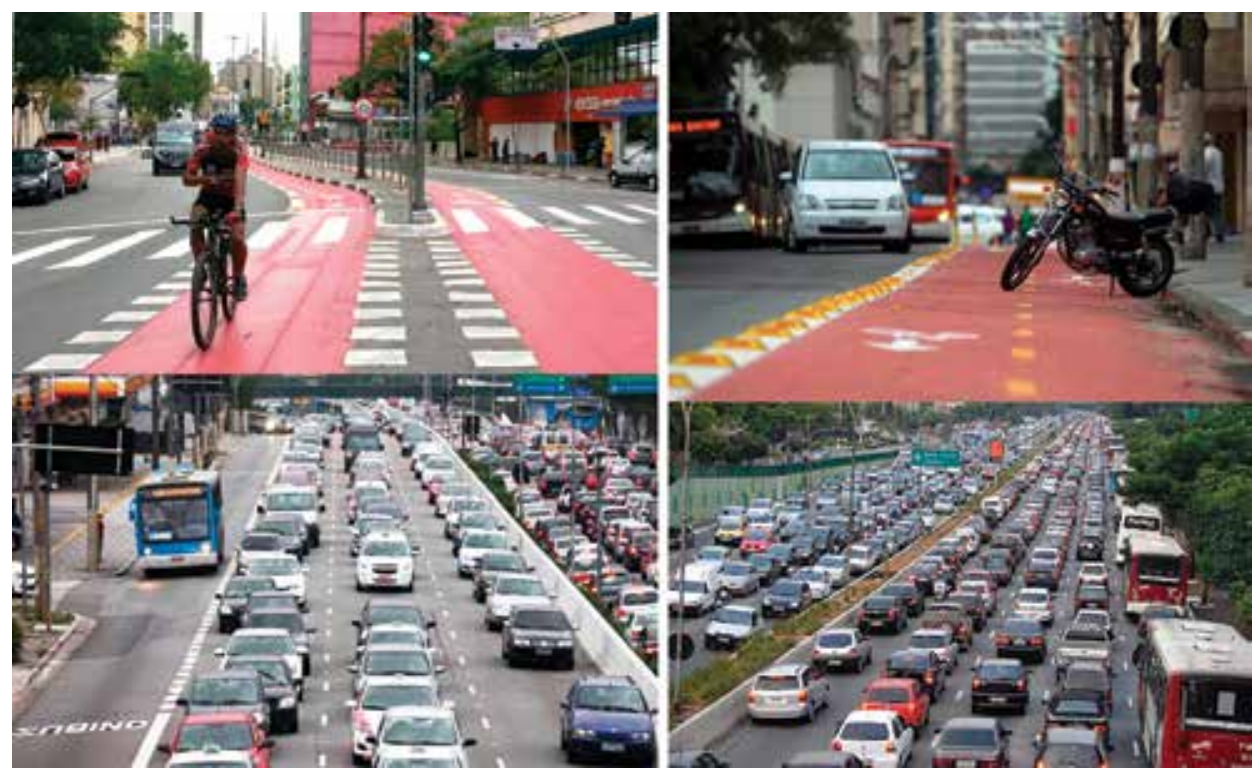

Estas acciones fueron criticadas por un sector de la población con mayor poder adquisitivo, bajo la alegación de que se aumentaría las horas de tránsito y dificultaría el acceso a los estacionamientos. Como contraparte, el grueso de la población, en especial aquellos con un menor poder económico, apoyaron la mayoría de las propuestas de Haddad. Es necesario esperar para observar si la llamada "Reforma Urbana" puesta en marcha será efectiva, esto contando con el apoyo popular, o si bien poco a poco será fragilizada por los intereses de los grupos económicos más poderosos, de los medios derechistas y de otros sectores públicos y privados que tienen intereses sobre la ciudad. En otras prefecturas regionales ya se han anunciado procesos similares de reforma urbana, pero hasta el momento no hay una articulación nacional que sea coordinada por el Gobierno federal.

\section{Sistemas de movilidad urbana}

A comienzos del presente siglo el proceso de globalización económica se ha intensificado en función de una serie de avances en las telecomunicaciones y los transportes, y en el que la dinámica del desarrollo económico-social pasa y se experimenta en los centros urbanos, situación que nos llevaría a afirmar que este es el siglo de las ciudades, pues actualmente son alrededor de 3.600 millones de personas en el mundo las que las habitan. Según datos de la ONU, esta cifra equivale aproximadamente a un aumento de cinco veces lo que era hace 60 años, representando un crecimiento promedio anual de 2,72\%. Sin embargo, lo que más preocupa no es solo el ritmo de crecimiento global de las poblaciones urbanas, sino su carácter: la mayor parte de ese crecimiento se debe al surgimiento de metrópolis en países en via de desarrollo, como resultado de un proceso de éxodo rural (en un primer momento) que no va a encontrar respuestas eficientes por parte de los gobiernos locales frente a la generación de infraestructura urbana que pueda soportar dicha explosión demográfica. En estos países encontramos problemas urbanos que van desde la ausencia de saneamiento básico hasta la dificultad en la movilidad dentro de las ciudades. Sin embargo, y paradójicamente como factores positivos de la urbanización de las últimas décadas,
Figura 13. Nuevas ciclovías y franjas de autobuses en São Paulo, Brasil Fuente: Adaptación de los autores (2015) 
podemos citar el mejoramiento de las condiciones de vida en general, incluyendo el nivel de salubridad, el acceso a la salud pública y las condiciones alimenticias de la población, contribuyendo estos factores a la disminución de la mortalidad y el aumento de la longevidad, y así, consecuentemente, al incremento poblacional de dichos países. De cierta manera, la ciudad latinoamericana de finales del siglo $X X$ se convirtió en una esperanza para las personas que estaban dejando los campos y las regiones más pobres en busca de unas condiciones de vida mucho más dignas.

Ahora bien, uno de los problemas que deben enfrentar las grandes ciudades como receptáculos de población es la movilidad, la cual no se limita únicamente al espacio de la ciudad, sino a las conexiones con otros lugares. Por lo tanto se encuentran singularidades locales y, o regionales que son determinantes en la elaboración y ejecución de planes o programas urbanos de movilidad. En lo que se refiere a los sistemas de transporte público de los países europeos en crisis (después del 2008), por ejemplo, se observa una fuerte presión por el aumento de las tarifas y la reducción de las subvenciones estatales, debido a la crisis fiscal de los Estados, de las exigencias de los acreedores de la Unión (presión neoliberal para la desestatización y reducción de los derechos sociales, por ejemplo). La comprensión integral de estos factores, en especial, los económicos, acaban por ejercer presiones en el reparto y aplicación de recursos que, directa o indirectamente, afectan la calidad y la movilidad urbana.

Dentro de las estrategias para mejorar la movilidad y hacer de esta un proceso mucho más incluyente y equitativo, encontramos algunos ejemplos importantes como la transformación urbana experimentada por la ciudad capital colombiana de Bogotá durante los últimos 15 años, la cual tiene una población aproximada de siete millones de habitantes. Para 1998 se creó el plan director de Bogotá, que priorizaba, entre otros aspectos, la creación de una red cicloviaria de $340 \mathrm{~km}$ de vías exclusivas para ciclistas. La construcción se inició en 1999 y, para el 2000 se habían construido alrededor de 180 km de ciclovías (IDU, 2016).

La ciudad de Bogotá, a pesar de su gran dimensión urbana y de la desigualdad social que aún es evidente, es un ejemplo positivo de América del Sur. Allí, las ciclobandas de domingo, que sustituyen el uso de los coches en las vías principales, ya se daban desde la década de 1980. En consecuencia de acciones gubernamentales, la dependencia de vehículos automotores particulares pasó a disminuir y la restricción al uso de los automóviles vino antes de las mejoras para la movilidad urbana. El impacto de la administración del alcalde Enrique Peñalosa (1998 a 200I) sobre el modo en que las personas se desplazan en la ciudad todavía es resaltado como un elemento transformador en conferencias de urbanismo. Para una ciudad que ya ha sido sinónimo de atascos, ahora más de la mitad de todos los viajes en la capital colombiana se hacen en autobús. Para el 200I, durante el último año del mandato de Peñalosa, Bogotá recibió el premio de calidad urbana Stockholm Challenge por el sistema de transporte Transmilenio, que fue inspirado en el Bus Rapid Transit brasileño de Curitiba-PR.

Por otro lado, el desplazamiento pendular de personas, de bienes y de servicios, acarrea impactos en las regiones metropolitanas y grandes capitales, localidades de mayor concentración poblacional. La movilidad urbana deficiente es un limitante al momento de acceder a oportunidades de mejoramiento urbano, y afecta, en particular, al sector menos favorecido económicamente de la ciudad. La aglomeración urbana demanda con urgencia armonía y agilidad en el desplazamiento de bienes y personas, el cual debería llevarse a cabo con eficiencia, confort y seguridad, además de mitigar los impactos am- 
bientales, visuales y de contaminación sonora y atmosférica, resaltando también modelos de minimización de la exclusión social. De igual forma, algunas investigaciones señalan a la movilidad como un promotor, entre las demás infraestructuras, de la economía urbana, interfiriendo directamente en la dinámica económica de las ciudades y regiones. Es en este sentido que la planificación del transporte urbano a mediano y largo plazo es imprescindible.

En el contexto brasileño, caracterizado por la adopción del modelo carretero de movilidad (intra e interurbana) después de los años 1950, las metrópolis brasileñas sufren en la actualidad con la congestión y elevado costo en el precio de las tarifas, por la oferta de servicios precarios, ineficientes y desfasados que acarrean la significativa disminución de la calidad de vida de las ciudades. Algunas de ellas como Brasilia, capital federal construida en los años 1960 y proyectada para la circulación vial, según los parámetros incluidos en la Carta de Atenas y los preceptos modernistas de Le Corbusier, enfrenta actualmente problemas crecientes de movilidad urbana. Su población proyectada inicialmente para 500 mil habitantes, hoy tiene más de 4 millones en su región metropolitana (IBGE, 20I4), y está bastante polarizada para el Plan Piloto (centro político nacional), con un alto grado de movilidad mononuclear. El aumento del número de vehículos en la última década, como consecuencia de los incentivos económicos para la adquisición de bienes de consumo (entre ellos el coche), y de la mejora del ingreso económico en general, fue el detonante para que se diera un aumento signifcativo en la congestión vial, no solo de Brasilia sino de muchas ciudades brasileñas.

Otro factor agravante de este escenario urbano es la dispersión de las ciudades de forma intensa y en baja densidad, que acaban por segregar las porciones urbanas en regiones cada vez más distantes de los centros de las ciudades, con una infraestructura urbana deficiente y crecientemente onerosa. Este fenómeno de dispersión es bastante recurrente en las grandes y medianas ciudades de Brasil desencadenándose después de la década de 1970. Sin embargo, ese diseño de ciudad dispersa se ha mantenido, en ausencia de políticas urbanas actuales que sean eficientes, llevando así a la concatenación de la intensificación del cuadro de dispersión y la segregación al interior de las ciudades.

Al respecto, la movilidad urbana es un agente determinante para la generación de dinámicas de usos y la valorización de áreas urbanas. Su planificación engloba la escala peatonal, ciclística (red de ciclovías), viaria y ferroviaria. Estos subsistemas de movilidad deben actuar en sinergia para obtener una mayor eficiencia en los desplazamientos, $y$ deberán estar cobijados por un diseño urbano de mayor densidad y conectividad, con uso mixto, capaz de establecer un uso optimizado de las partes de la ciudad y, consecuentemente, alcanzar mayores índices de vitalidad urbana y uso de los espacios públicos.

Entre las estrategias de mejora y perfeccionamiento de la movilidad en emprendimiento intermodal, las iniciativas públicas y privadas deben priorizar la gestión del transporte de masas, por encima de todo, transporte sobre rieles, desarrollando logística de integración local, regional, nacional e internacional.

Para Cheptulin (1982) a menos que podamos actuar fuera del marco del sistema (del modo de producción hegemónico), las cuestiones esenciales para ser tratadas de inmediato se refieren al:

- Fortalecimiento de los municipios estatales asociados a la planificación física de los sistemas de transporte y su fiscalización. 
Figura 14. Incremento poblacional frente a la flota de vehículos en Brasil entre 2000 a 2012 Fuente: Elaborado por los autores (2015) a partir de Datos Denatran (2012) y IBGE (2015).
- Gestión contable del capital de transportes y garantía de efectividad de la Ley de Movilidad Urbana.

- Canales para la asignación de recursos orientados a la provisión de infraestructura específica para el transporte público, como medida para aumentar la eficacia operativa del sistema de transporte.

- Provisión de intermodalidades con distintos modos y modales de transporte (incrementa la eficacia y retira un poco de poder de las familias que monopolizan el transporte público por ómnibus).

- Generación de condiciones para el aumento de los subsidios al sector.

La demanda de nuevas infraestructuras, tales como corredores exclusivos de BRT y la implementación y ampliación de los metros y, aún en implementación, de los VLT es notoria y se exhibe en diferentes metrópolis brasileñas. La Fundación Dom Cabral, por ejemplo, en un estudio realizado en 2012 muestra que en realidades como la de la Grande São Paulo (región metropolitana), cada año la congestión aumenta en un 17\%, y en la Grande Belo Horizonte y en Río de Janeiro alrededor del 14\%, reflejandose directamente en los tiempos perdidos durante dichos intervalos de congestión. En Río de Janeiro, la referida encuesta apuntó a un aumento de $\mathrm{l}$ h y 52 minutos para $2 \mathrm{~h}$ y 49 minutos de tiempo en tránsito, y en São Paulo, $3 \mathrm{~h}$ y 30 minutos por día. Esto también repercute directa e indirectamente sobre la producción social de riqueza, visto el ejemplo de la capital paulista, donde se estiman pérdidas en la congestión, en el orden de $\mathrm{R} \$ 40$ mil millones al año en recursos.

En promedio, las ciudades brasileñas duplicaron el número de vehículos totales en una década, de 29,7 millones en 2000 a 64,8 millones de vehículos en 2010 (incremento del I I8\%), mientras la población total aumentó alrededor de I3\%. Y ese índice es mucho mayor en regiones metropolitanas y ricas, pues la adquisición de vehículos está ligada al poder adquisitivo de la población (figura 14).

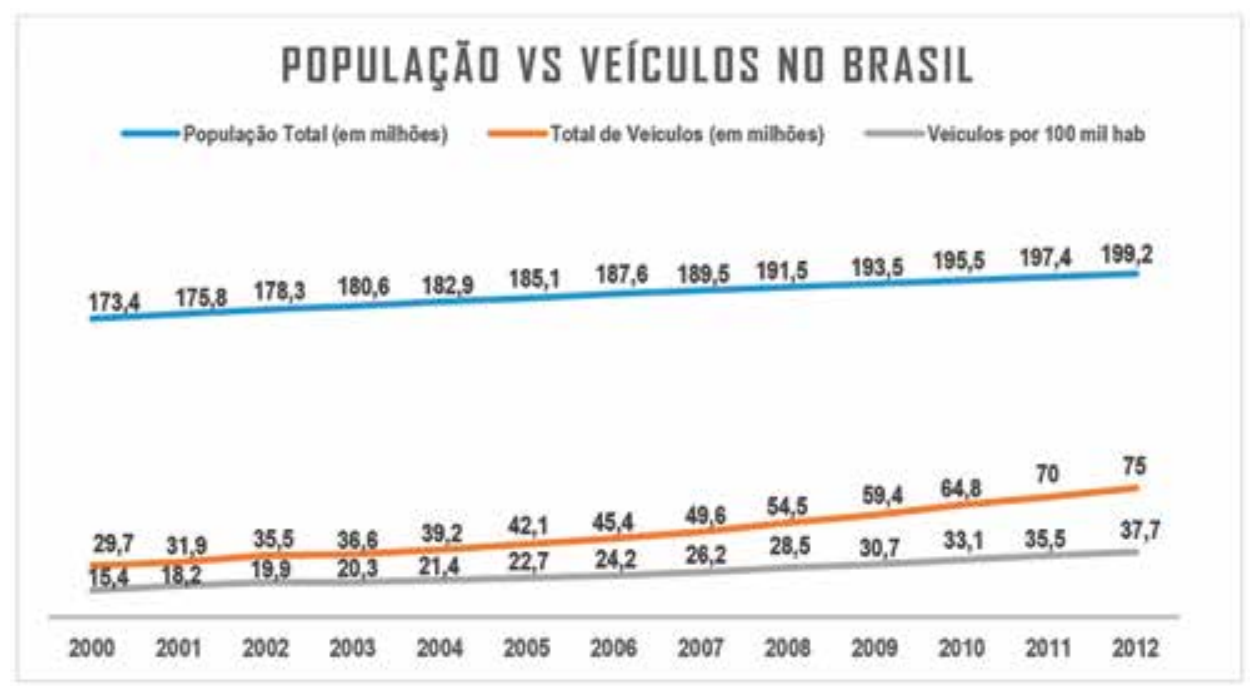

Ahora bien, la movilidad urbana es solo uno de los criterios para transformar la calidad de vida de las ciudades, pero la poca eficiencia y calidad que van en aumento, sumadas a la negligencia gubernamental pueden ser, y de hecho lo han sido en los últimos años, el detonante colectivo para que la sociedad se movilice, pues afecta directamente la rutina diaria que transcurre entre el trabajo, la vivienda y los momentos de ocio de los habitantes 
urbanos, en especial, la de los menos favorecidos. La inversión en esta área, además de dinamizar la economía urbana, puede establecer mayor justicia socioespacial, minimizando las crisis y conflictos frente a la gestión de las ciudades en expansión. Lo que se ha verificado en las últimas dos décadas principalmente, es la actuación del planeamiento urbano de gran parte de las ciudades brasileñas (y de América Latina), a favor del aumento del flujo del automóvil y del mantenimiento y fortalecimiento del denominado ciclo de dependencia automotora de las ciudades (figura I5).

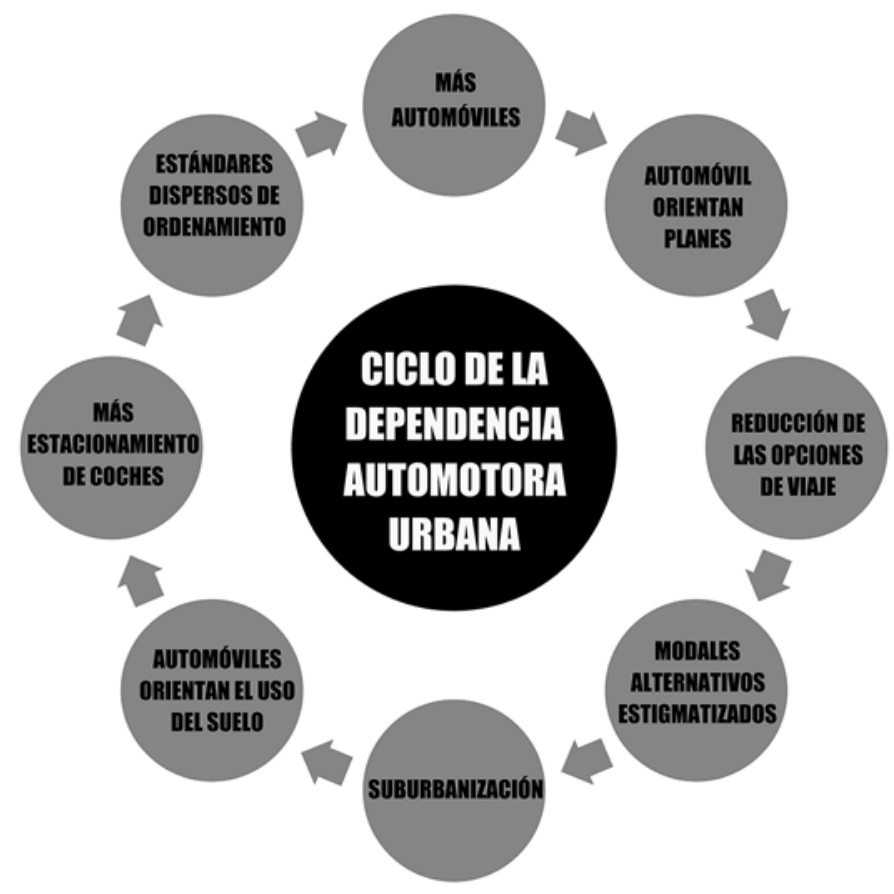

\section{CONSIDERACIONES FINALES}

El modelo occidental de sociedad basado en la cultura del automóvil generó, para diversas ciudades que heredaron del siglo $X X$, una infraestructura orientada al uso del transporte individual motorizado, una "cultura automotriz" relativamente sedimentada. Especialmente en determinadas metrópolis, estos factores implican el agravamiento de fenómenos como la degradación del medio ambiente, la desigualdad social, la segregación espacial y el bajo grado de accesibilidad. Al mismo tiempo, se observa en grandes centros de todo el mundo la expansión de medidas susceptibles de mejorar o revertir esas situaciones, como la implantación de peajes urbanos, la construcción de paseos públicos y el incentivo a la llamada "movilidad activa". Sin embargo, la morfología urbana, su densidad y los niveles de dispersión pueden agravar el cuadro de movilidad y desagregación (o fragmentación) social de la ciudad, aumentando las disparidades, las desigualdades y las injusticias urbanas.

Esta paradoja urbana en América Latina exige una comprensión más allá de los hechos inmediatos de la presente coyuntura. Resulta importante investigar la dinámica de las relaciones económicas y políticas entre las fuerzas presentes en las ciudades con aquellas que vienen comandando el desarrollo de las relaciones capitalistas en este continente entre el final del siglo $X X$ y el inicio del $X X I$. Tales relaciones fueron siempre biunívocas, especialmente en aquellos países que experimentaron la expansión del capitalismo industrial tardío. En otros términos, en muchos países del continente se estableció una relación de sinergia
Figura 15. Ciclo de dependencia automotoro actuante en las ciudades contemporáneas Fuente: Elaborado por los autores (2015) 
entre el capitalismo industrial y lo que se puede denominar "capitalismo urbano", por la cual se pudo legitimar el patrón liberal del desarrollo latinoamericano. La ciudad fue, por lo tanto, históricamente controlada por las fuerzas del mercado como fundamento de un bloque de poder que comandó la inserción en la expansión del moderno sistema capitalista. Al mismo tiempo, la ciudad fue el gran promotor de las economías más prominentes de esta región, estableciendo una vía doble de posibilidades económicas, conocimiento tecnológico agregado y urbanización. Este hecho político-económico deriva de la acomodación de las fuerzas dominantes internas de los países latinoamericanos a la inserción asociada a las fuerzas liberales internacionalizantes que surgen y se expanden desde el siglo XVI, a partir del núcleo del moderno sistema capitalista.

En cuanto a la complejidad de estas cuestiones, el presente artículo tenía como objetivo principal discutir el núcleo de los problemas que involucran a las ciudades latinoamericanas, evidenciando aspectos particulares de lo cotidiano de las ciudades brasileñas, en un estudio de la coyuntura, de la formación social, y de las mencionadas crisis urbanas, debido a la ausencia de recursos, proyectos o acciones gubernamentales. Es por tanto que el establecimiento de métodos para la planificación eficaz y la acción sobre la realidad inmediata es un camino necesario para las ciudades de América Latina, frente a las demandas urbanas existentes y a los nuevos desafíos de crecimiento urbano y riesgos ambientales que se avecinan.

Dentro del desarrollo de un pensamiento analítico, el carácter y la forma de la urbanización no pueden separarse de la naturaleza del desarrollo de una sociedad determinada, pues existe el problema de la fragilidad de la urbanización en algunos puntos del territorio (dispersión y vacíos), y de la exagerada concentración en otros puntos (concentración y compactación), y que necesitan ser resueltos por el gestor público, a partir de la observación de las condiciones económicas y sociopolíticas de cada realidad local. Es cierto que la gestión urbana, casi exclusivamente, privilegia sectores de la economía, así, las comunidades más frágiles económicamente acaban por sufrir con las alternancias de la gestión y la discontinuidad de las políticas urbanas que no atienden a sus intereses. El equilibrio entre las esferas de lo económico, de lo social y de lo ambiental debe ser establecido por medio de la actuación participativa de los diversos sectores de la sociedad, de esta forma, la eficiencia de los canales de comunicación y participación son herramientas importantes en la democratización urbana, que aún se encuentra en construcción en el escenario latinoamericano. En otros términos, el acceso a las redes sociales y los medios de comunicación alternativos ha ofrecido una nueva fuerza en la política urbana, teniendo en cuenta que las comunidades pasan a conectar acciones e intereses en favor de la colectividad. Esta nueva forma de manifestación de las fuerzas de poder que emerge de las periferias está cambiando la relación entre la gestión territorial y las demandas locales. Dicho fenómeno ha llegado a movilizar a los habitantes en las calles, barrios, comunidades o segmentos sociales para cuestionar determinadas acciones de la gestión municipal o reivindicar mejoras de infraestructura y servicios públicos.

En cierta manera, las carencias de movilidad y el aumento de la violencia urbana acaban por actuar sobre la especulación y valorización de determinadas áreas de las ciudades elegidas por la iniciativa privada y por los gobiernos como ejes prioritarios de inversión y valorización, en contraposición a las áreas más pobres, estas centrales o periféricas que padecen de infraestructuras chatarra, con ausencia de equipamientos urbanos, de accesibilidad deficiente, entre otros elementos que influyen sobre la calidad de la vida urbana. En estos términos, los problemas generados por una planificación pro-especulativa, bastante recurrentes en las grandes ciudades de América Latina, son utilizados como potencializadores de las ganancias y de la valorización de áreas nobles, objetos de la acción de la industria inmobiliaria y construcción civil, alimentando un ciclo vicioso que prioriza inversiones en 
sectores ricos de la ciudad, y deja al margen las áreas más pobres. La planificación urbana pasa por la gestión territorial igualitaria y distributiva de recursos y oportunidades en las ciudades en desarrollo. En este ámbito, los ejemplos urbanos chilenos y colombianos parecen apuntar a caminos positivos, mientras que países como Brasil acentúan sus desigualdades socioespaciales en las grandes y medianas ciudades, en intensa dispersión.

La ruptura de este ciclo de urbanización especulativa es necesaria bajo varios aspectos (figura 16). Comprenderlo, percibir la actuación del mercado de tierras, promover el incremento de la economía urbana en la escala del lugar y de los barrios conforme a las necesidades socioeconómicas urbanas, son algunos de los desafíos anhelados para las ciudades latinoamericanas.

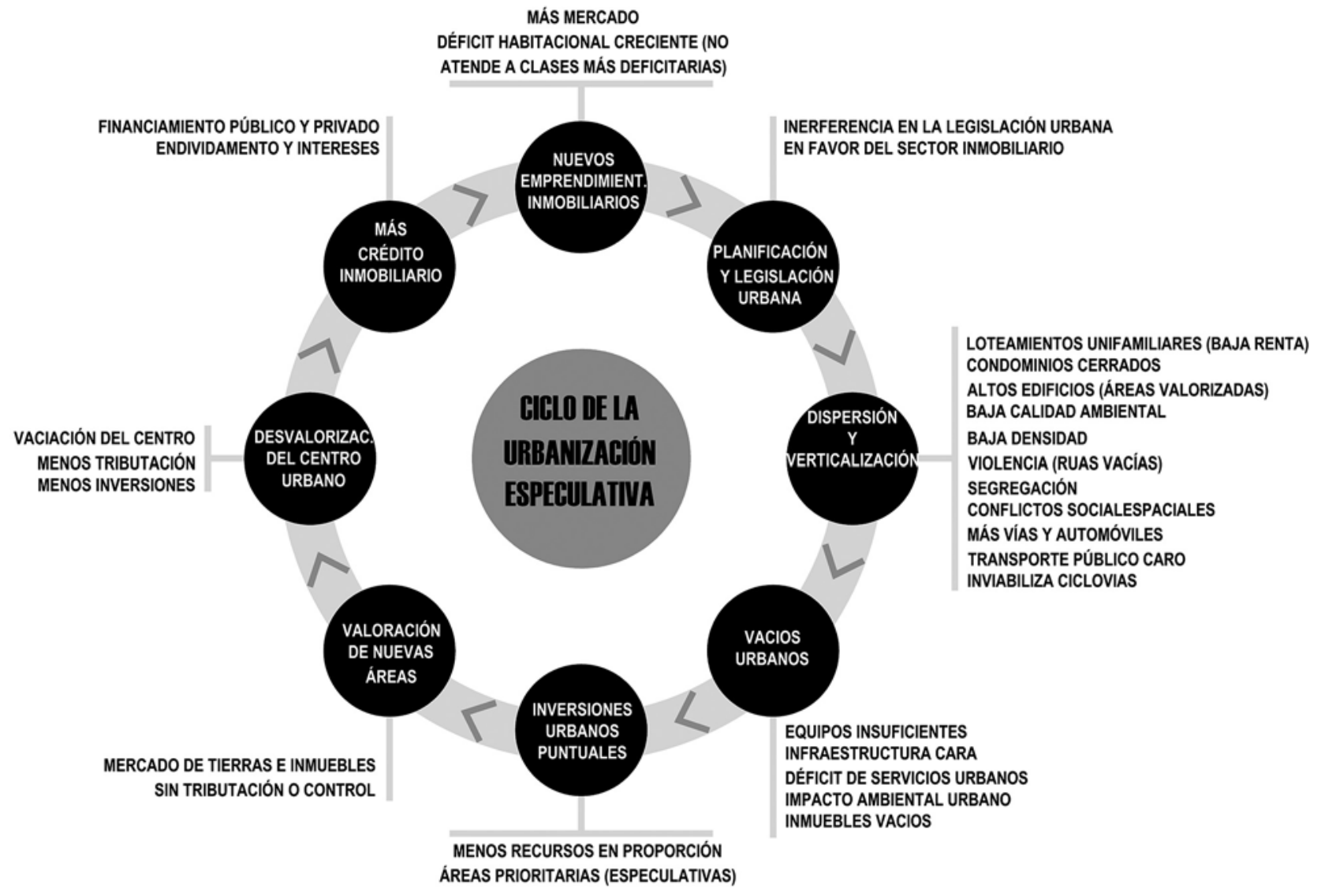

Sin embargo, cabe enfatizar las actuaciones más emergentes de la gestión urbana dentro de este contexto:

I. Planificación y legislación urbana: distribuido y orientado por estudios aplicados a los barrios y controlado (y comparado) por indicadores de calidad urbana. El diseño urbano debe buscar criterios cualitativos y cuantitativos, a partir de criterios de análisis multiescalar y compuesto por multivariadas urbanísticas.

2. Verticalización y dispersión: regulación urbana de control a la verticalización urbana y periferización. Esto pretende mejorar el acceso del peatón a la calle y a la vecindad, así como minimizar los impactos ambientales de la verticalización exagerada en cuanto a la dispersión urbana de baja densidad y monofuncional.

Figura 16. Ciclo de la urbanización especulativa en las ciudades contemporáneas, en particular, de los países en desarrollo Fuente: Elaborado por los autores (2015) 
3. Densidad urbana: aumento de la densidad poblacional urbana (densidad bruta y líquida), conforme a las demandas locacionales (implantación de la cuadra en el contexto urbano y viario), uso mixto y mayor acceso de peatones a las calles y vías públicas (con el uso de cuadras abiertas y no amuralladas). La mayor densidad puede optimizar las inversiones públicas sobre el territorio (equipamientos, movilidad y servicios), y potenciar la economía urbana con el uso mixto y emprendimientos diversos más cercanos a la vivienda.

4. Control de la especulación inmobiliaria (tributación) y reordenación de los vacíos urbanos en favor de inversiones en la ciudad y vivienda social.

5. Coordinar inversiones públicas puntuales que apunten a la especulación y valorización de nuevas áreas privadas, pues estas deben ser incorporadas por el capital privado. Distribuir servicios y equipamientos urbanos conforme a la demanda poblacional y los rayos de desplazamiento peatonal.

6. Rehabilitar los centros urbanos con viviendas para diversas franjas de renta, implementando uso mixto, equipamientos e instituciones públicas, y eliminar edificaciones vacías y en desuso.

7. Promover centros secundarios y terciarios en los barrios conectados por transporte colectivo de masa (para distancias y demandas mayores) y modales alternativos peatonales y ciclísticos (para distancias inferiores a $5 \mathrm{~km}$ ).

Los equipos urbanos (plazas, parques, polos deportivos, de ocio, puestos de salud, hospitales, guarderías, escuelas, puesto de policía, entre otros), así como los demás servicios públicos deben ser distribuidos y democratizados. En un primer momento, de forma cuantitativa, pero acompañada de un incremento cualitativo progresivo. Así las demandas sociales y espaciales son acompañadas por el proceso de densificación, aumento de renta ( $y$ tributos) y acceso para las personas a estos servicios públicos.

Se entiende que la movilidad urbana es un tema relevante para las ciudades actuales, pues determina el nivel de accesibilidad y flujos de los individuos, mercancías, servicios, y sus respectivos costos de operación, mantenimiento y eficiencia. Por consiguiente, la vivienda adecuada, la educación, el saneamiento urbano, sumados a los incrementos económicos distributivos, deben actuar en sinergia con las demandas de las ciudades. Es un escenario complejo de gestión territorial, aún más tratándose de una América Latina que todavía ocupa un papel periférico en la coyuntura económica global, y así, más susceptible a las oscilaciones y crisis de mercado internacional y con una masiva población urbana marginada, pero creciente hasta 2050 , según las previsiones citadas. Planificar y priorizar las inversiones urbanas a mediano y largo plazo, con la implementación de políticas urbanas continuadas, son procedimientos esenciales para la buena gestión de recursos capaces de reactivar la economía urbana y la generación de más ingresos y empleo.

\section{REFERENCIAS}

Agenda 2 I Brasileira. (2000). Bases para discussão. Brasília-DF.

Alcaldía de Bogotá. Proyecto de Acuerdo No. 016 de 2008. Bogotá. Recuperado de http://www.alcaldiabogota.gov.co/sisjur/normas/Normal.jsp?i=28684

Banco Interamericano de Desarrollo - BID. (2012). Comunicados de imprensa. Estudo do BID revela que América Latina e o Caribe enfrentam um déficit de habitação considerável e 
crescente. Recuperado em 23 março 2017 de http://www.iadb.org/pt/noticias/comunicadosde-imprensa/2012-05- I4/deficit-habitacional-na-america-latina-e-caribe, 9978.html.

Cheptulin, A. (1982). A dialética materialista: leis e categorias da dialética. São Paulo: Alfa-Ômega.

Fundação Dom Cabral. (2013). Brasil. Recuperado em <http://www.fdc.org.br/pt/>.

Instituto Brasileiro de Geografia e Estadística - IGBE. (2008). Projeção da População do Brasil por Sexo e Idade para o período 1980- 2050. Rio de Janeiro: IGBE.

Instituto de Desarrollo Urbano - IDU. (2016). Bogotá. Recuperado de: https://www. idu.gov.co/page/cicloruta

Instituto de Investigaciones y de Planificación Urbana de Curitiba - IPPUC. (2015). Brasil. Recuperado de http://www.ippuc.org.br/

Instituto de Pesquisas Econômicas Aplicadas - IPEA. (20I2). Notícias. Brasília, Brasil. Recuperado em http://www.ipea.gov.br/portal/index.

Instituto de Planejamento Urbano de Florianópolis - IPUF, Santa Catarina, Brasil. Recuperado de <www.pmf.sc.gov.br/entidades/ipuf>

Nunes da Silva, F. (20I3). Mobilidade Urbana: os desafios do Futuro. Cadernos Metrópole, 15(30). Recuperado de http://www.cadernosmetropole.net/component/content/ article/3I/5I-30.

ONU, Department of Economic and Social Affairs. (2014). The population division. Recuperado em http://esa.un.org/unpd/wup/.

Política Nacional de Mobilidade Urbana. Lei 12.587/20 I2. Disponível em http://www. planalto.gov.br/ccivil_03/_ato20I I-2014/20I2/lei/ll2587. html

United Nations, Department of Economic and Social Affairs, Population Division. (2014). World Urbanization Prospects: The 2014 Revision. (Custom data acquired via website). Recuperado de <http://esa.un.org/unpd/wup/>.

Vasconcellos E. (1996). Transporte urbano nos países em desenvolvimento. Sao Paulo: Editoras Unidas. 